\title{
The electrocardiogram in ST elevation acute myocardial infarction: correlation with coronary anatomy and prognosis
}

\author{
Y Birnbaum, B J Drew
}

Postgrad Med J 2003;79:490-504

The electrocardiogram is considered an essential part of the diagnosis and initial evaluation of patients with chest pain. This review summarises the information that can be obtained from the admission electrocardiogram in patients with ST elevation acute myocardial infarction, with emphasis on: (1) prediction of infarct size, (2) estimation of prognosis, and (3) the correlations between various electrocardiographic patterns and the localisation of the infarct and the underlying coronary anatomy.

See end of article for authors' affiliations

Correspondence and reprint requests to:

Professor Yochai Birnbaum

Division of Cardiology, University of Texas Medical Branch, 5, 106 John Sealy Annex, 301 University Blvd, Galveston, TX 77555-0553, USA yobirnba@utmb.edu

Submitted 14 August 2002 Accepted 28 May 2003
$\mathrm{F}$ or a long time the 12-lead electrocardiogram (ECG) was considered an essential part of the diagnosis and initial evaluation of patients with chest pain. Patients with ST elevation or new left bundle branch block are usually referred for immediate reperfusion therapy, whereas those without ST deviation or those with predominately ST depression are usually treated conservatively initially. ${ }^{12}$ Patients are diagnosed as having anterior, inferior-posterior, or lateral myocardial infarction based on the patterns of ST deviation and assessment of risk is usually based on simple crude measurements of the absolute magnitude of ST segment deviation or the width of the QRS complexes. $^{3}$

However, there is much more information concerning the exact site of the infarct related lesion, prediction of final infarct size, and estimation of prognosis that can be obtained from the initial ECG without extra costs or time. Although some clinicians feel that with the increased use of primary coronary interventions in patients with ST elevation acute myocardial infarction this information is no longer needed, there are many instances in which even with immediate coronary angiography, identification of the infarct related site and estimation of the myocardial area supplied by each of the branches distal to the infarct related coronary artery occlusion is difficult. In some patients, more than one lesion may be found and identification of the acutely thrombosed lesion may not always be apparent. Figure 1 is an example of a patient with inferior acute myocardial infarction who underwent primary coronary intervention. Coronary angiography revealed complete obstruction of all three major coronary arteries. The culprit lesion was determined to be the left circumflex artery using both the angiographic and ECG criteria. In other cases, complete occlusion of side branches at bifurcation of coronary arteries may be completely missed during coronary angiography.

It is important to appreciate that the ECG provides information about a totally different aspect of pathophysiology in acute myocardial infarction than does the coronary angiogram. Coronary angiography identifies vessel anatomy whereas the ECG reflects the physiology of the myocardium during acute ischaemia. For this reason, it is possible to observe severe coronary stenoses upon angiography without ECG evidence of acute ischaemia. Moreover, it is possible to observe restored vessel patency upon angiography with ECG evidence of ongoing ischaemia due to "no-reflow", reperfusion injury, or myocardial damage that has already developed before reperfusion occurs. Thus, while coronary angiography remains the "gold standard" for identifying the infarct related artery, the ECG remains the gold standard for identifying the presence and location of acute myocardial ischaemia. Moreover, with current imaging techniques, including contrast ventriculography, echocardiography and radionuclide perfusion scans, differentiation of ischaemic but still viable from necrotic myocardium during the acute stage of myocardial infarction is impossible.

This review will concentrate on the information that can be obtained from the admission ECG in patients with ST elevation acute myocardial infarction. In particular, we shall discuss the association of various ECG patterns of the acute phase of myocardial infarction with estimation of infarct size and prognosis and the correlation of various ECG patterns and the underlying coronary anatomy. We shall concentrate mainly on the acute phase of myocardial infarction (ST segment elevation with upright $\mathrm{T}$ waves) in patients without intraventricular conduction defects.

\section{FACTORS THAT DETERMINE PROGNOSIS IN ACUTE MYOCARDIAL INFARCTION (BOX 1)}

The immediate prognosis in patients with acute myocardial infarction is inversely related to the amount of myocardial reserves (total myocardial mass less the myocardium involved in the present myocardial infarction (ischaemic area at risk),

Abbreviations: $\mathrm{Cl}$, confidence interval; $\mathrm{ECG}$, electrocardiogram; LAD, left anterior descending; SPECT,

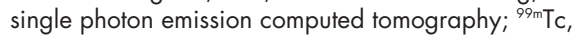
technetium $99 \mathrm{~m}$ 


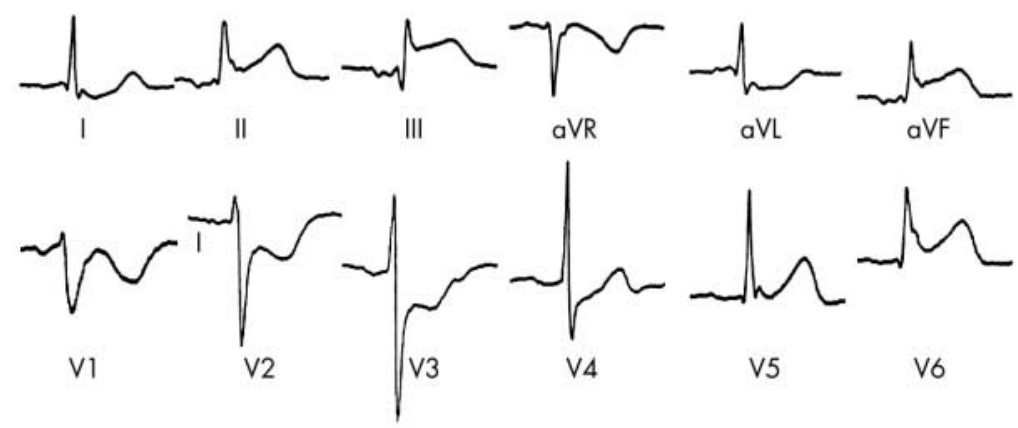

Figure 1 A 54 year old man with two hours of chest pain. (A) The ECG shows ST elevation in the inferior leads and V6 and ST depression in I $\mathrm{aVL}$, and $\mathrm{V} 1-\mathrm{V} 4$. (B) Angiography of the left coronary artery revealed total occlusion of the left anterior descending (black arrow) and the lef circumflex (white arrow) arteries. (C) Angiography of the right coronary artery showed complete occlusion of the artery.
B

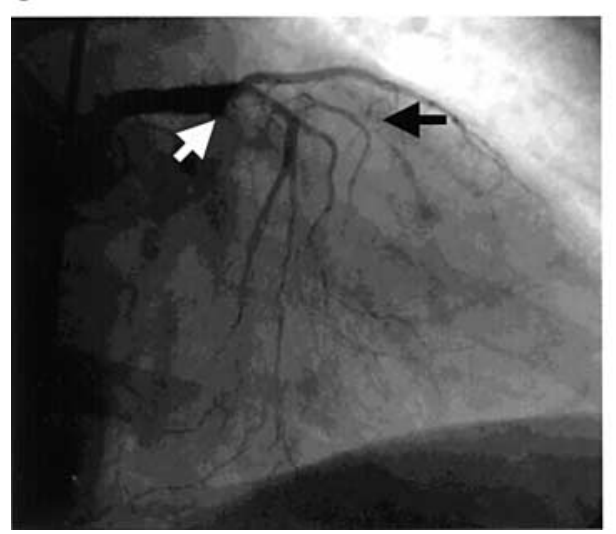

C

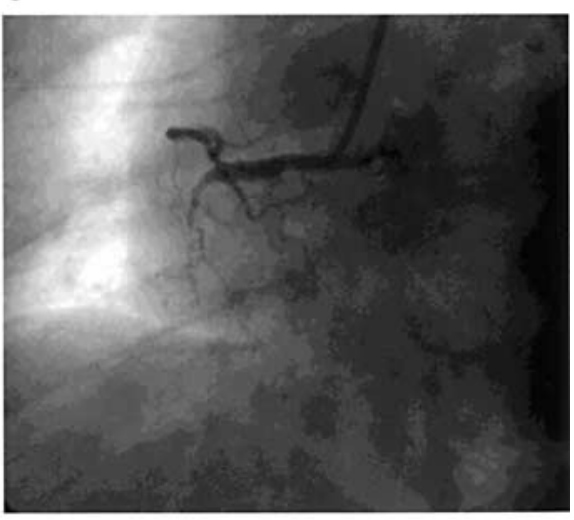

Box 1: Variables that affect the immediate prognosis in acute myocardial infarction

- Size of the ischaemic myocardium at risk.

- The percent of the ischaemic myocardium at risk that has already undergone irreversible necrosis.

- The "severity" of ischaemia (the expected rate of progression of myocardial necrosis).

- Presence of old myocardial infarction or fibrosis (myocardial reserves).

- Presence of "ischaemia at a distance" due to existence of stenotic lesions in other coronary arteries.

zones with scars due to previous myocardial infarction or fibrosis, and remote ischaemic myocardial segments supplied by critically narrowed coronary arteries). Among patients without prior myocardial infarction and without major pre-existing stenotic lesions in the coronary arteries, prognosis is related to the size of the ischaemic myocardium supplied by the culprit coronary artery distal to the occlusion. However, among patients with low myocardial reserves due to previous myocardial infarctions or diffuse fibrosis, even relatively small infarction may be detrimental. Moreover, among patients with diffuse severe coronary artery disease, a small myocardial infarction may interfere with the delicate balance, and induce ischaemia in remote segments due to obliteration of collateral flow or due to the need for (compensatory) augmentation of contractility in the remote non-infarcted segments. Therefore, in addition to accurate diagnosis, there is a need for early estimation of the size of the ischaemic myocardium at risk and myocardial reserves.

The ECG may help in assessing the size of the myocardial ischaemic area at risk, may help in differentiation between subendocardial and transmural ischaemia, and may assist in identifying the presence of previous infarctions (abnormal Q waves in leads not involved in the present infarction. For example, abnormal Q waves in the precordial leads in patient with inferior ST elevation). ${ }^{4}$ Furthermore, some ECG patterns may indicate presence of diffuse coronary artery disease and remote ischaemia. ${ }^{5-7}$

On admission, part of the myocardial area at risk (supplied by the culprit coronary artery lesion) usually has already undergone irreversible damage. The proportion of the ischaemic area at risk that has undergone irreversible necrosis depends on the total ischaemic time, and on the rate of progression of the wavefront of necrosis. The rate of progression of necrosis is highly variable and is dependent on the presence of residual perfusion via collateral circulation ${ }^{8}$ or incomplete or intermittent occlusion of the infarct related lesion," and various metabolic factors including "ischaemic preconditioning". ${ }^{10}$ The severity of ischaemia, or the expected rate of progression of necrosis (if no reperfusion occurs immediately) should be assessed. It is plausible that immediate reperfusion will benefit especially patients with large ischaemic myocardium at risk that is still viable upon admission, but have "severe ischaemia" with relatively rapid rate of progression of myocardial necrosis.

\section{ELECTROCARDIOGRAPHIC CHANGES DURING THE ACUTE STAGE OF ST SEGMENT ELEVATION MYOCARDIAL INFARCTION}

Shortly after occlusion of a coronary artery, serial ECG changes are detected by leads facing the ischaemic zone (fig 2): first, the $T$ waves become tall, symmetrical, and peaked (grade I ischaemia); second, there is ST elevation (grade II ischaemia), without distortion of the terminal portion of the QRS; and third, changes in the terminal portion of the QRS complex appear (grade III ischaemia). ${ }^{11-13}$ These changes include an increase in the amplitude of the $\mathrm{R}$ waves and disappearance of the $\mathrm{S}$ waves. These changes in the terminal portion of the QRS are explained by prolongation of the electrical conduction in the Purkinje fibres in the ischaemic region. ${ }^{14}{ }^{15}$ 


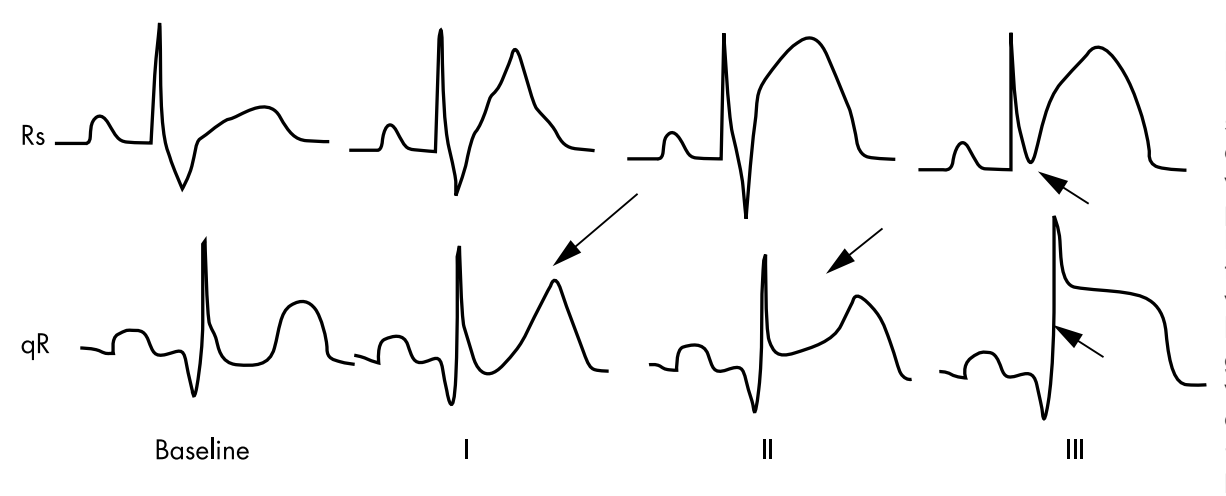

Figure 2 The grades of ischaemia. In leads with usual Rs configuration (leads V1-V3): grade I, tall symmetrical T wave without ST elevation; grade II, ST elevation without distortion of the terminal portion of the QRS complex; grade III, ST elevation with distortion of the terminal portion of the QRS (no $S$ waves in leads V1-V3) (arrow). In leads with usual qR configuration: grade I, tall symmetrical T wave without ST elevation; grade II, ST elevation with J point/R wave ratio $<0.5$; grade III, ST elevation with J point/ $R$ wave ratio $\geqslant 0.5$ (arrow).
The delayed conduction decreases the degree of cancellation, resulting in an increase in $\mathrm{R}$ wave amplitude in leads with terminal $\mathrm{R}$ wave and decrease in the $\mathrm{S}$ wave amplitude in leads with terminal $S$ wave on the surface ECG. ${ }^{14-18}$ The Purkinje fibres are less sensitive to ischaemia than the contracting myocytes. ${ }^{19}{ }^{20}$ Hence, for an alteration in the terminal portion of the QRS to occur, there should probably be a severe and prolonged ischaemia that would affect the Purkinje fibres. ${ }^{14} 21$ In patients with collateral circulation no changes were detected in the QRS complex during balloon angioplasty. ${ }^{10}$ Thus, absence of distortion of the terminal portion of the QRS, despite prolonged ischaemia, may be a sign for myocardial protection (probably by persistent myocardial flow due to subtotal occlusion or collateral circulation, or due to myocardial preconditioning). Disappearance of the $S$ waves in leads with terminal S (Rs configuration) (mainly leads Vl-3) can be easily recognised (fig 3).

In contrast, the absolute $\mathrm{R}$ wave height is influenced by many other variables. Therefore, the absolute $\mathrm{R}$ wave amplitude is not helpful in determining the severity of ischaemia. Changes in the $\mathrm{R}$ wave amplitudes can be detected reliably only on continuous ECG monitoring, since comparison of the admission ECG to previous ECG recordings is often difficult due to differences in ECG instruments and different placement of the precordial electrodes. Therefore, a second criterion for leads with terminal $\mathrm{R}$ configuration was developed. This criterion relates the J point of the ST to the R wave amplitude in leads with terminal $R$ waves ( $\mathrm{qR}$ configuration) (figs 2 and 4 ). ${ }^{11}{ }^{13}$

Although the transition between the grades of ischaemia is gradual and continuous, for practical clinical purposes we found it convenient to define grade II of ischaemia as ST elevation $\geqslant 0.1 \mathrm{mV}$ without distortion of the terminal portion of the QRS, and grade III as ST elevation with distortion of the terminal portion of the QRS (emergence of the J point $\geqslant 50 \%$ of the $\mathrm{R}$ wave in leads with qR configuration, or disappearance of the $\mathrm{S}$ wave in leads with an Rs configuration (figs $2-4) .{ }^{11}{ }^{22-26}$ Only later, the T waves become negative, the amplitude of the $\mathrm{R}$ waves decreases, and additional $\mathrm{Q}$ waves may appear. However, only the minority of patients with acute myocardial infarction shows grade III ischaemia upon admission. While the underlying mechanism for this difference is still unclear, grade III ischaemia has large implications concerning prognosis, as will be discussed later.

\section{DIAGNOSIS OF ACUTE MYOCARDIAL INFARCTION}

In a patient with typical symptoms, presence of ST elevation, especially when accompanied with reciprocal changes, is highly predictive for evolving acute myocardial infarction. However, several investigators reported that the sensitivity of the ECG for acute myocardial infarction may be as low as $50 \%{ }^{27-30}$ In most of these studies only one admission ECG was analysed. Hedges et al used the admission and a second ECG performed 3-4 hours after admission and found serial ECG changes in $15 \%$ of the patients. ${ }^{31}$ However, continuous or multiple ECGs over time or during fluctuations in the intensity of symptoms were not performed. Such repeated recording may improve the ability to detect subtle ischaemic changes. Furthermore, as determined by independent reviewers, $49 \%$ of the missed acute myocardial infarctions could have been diagnosed through improved ECG reading skills or by comparing the ECG to an old, baseline recording..$^{29}$ It should be remembered that acute myocardial infarction detected by raised creatine kinase MB levels or troponin I or T without ST elevation is not an indication for urgent reperfusion therapy. The only exception is new left bundle branch block. Menown et al studied the sensitivity and specificity of the admission ECG for diagnosing acute myocardial infarction by studying patients with $(n=1041)$ and without $(n=149)$ chest pain. The best ECG variables for the diagnosis of acute myocardial infarction were ST elevation $\geqslant 0.1 \mathrm{mV}$ in $\geqslant 1$ lateral or inferior lead or ST elevation $\geqslant 0.2 \mathrm{mV}$ in $\geqslant 1$ anteroseptal precordial lead. These criteria correctly classified $83 \%$ of subjects with a sensitivity of $56 \%$ and a specificity of $94 \%$. Changing the degree of ST elevation greatly modified both the sensitivity $(45 \%-69 \%)$ and the specificity $(81 \%-98 \%)$. The addition of multiple QRST variables (Q waves, ST depression, T wave inversion, bundle branch block, axes deviations, and left ventricular hypertrophy) increased specificity but improved overall classification only marginally.32

\section{ESTIMATION OF THE SIZE OF THE ISCHAEMIC MYOCARDIUM AT RISK}

The extent of regional wall motion abnormalities can be easily appreciated soon after admission by two dimensional echocardiography or left ventriculography. However, in both methods differentiation between old scars and the acutely ischaemic but viable zones is not always possible. Due to the effect of "stunning", regional wall motion may persist for long periods of times after reperfusion occurred..$^{33}$ Moreover, differentiation of transmural from subendocardial ischaemia/ infarction is not always possible since akinesis may occur when only the inner myocardial layers are ischaemic. ${ }^{34}$

Several studies have tried to estimate the ischaemic area at risk or final infarct size with the admission ECG. In these studies, either the number of leads with ST deviation (elevation and/or depression) ) $^{35-38}$ or the absolute amplitude of ST deviation ${ }^{35}{ }^{38-40}$ were used. However, the results were conflicting. Aldrich et al studied patients with acute myocardial infarction who did not receive thrombolytic therapy. ${ }^{35}$ The best correlation between the final ECG Selvester QRS scoring system (an estimation of infarct size) and the admission ECG was found using the magnitude of ST elevation in leads II, III, and aVF in inferior myocardial infarction and the number of leads with ST elevation in anterior myocardial infarction. ${ }^{35}$ However, in patients who received reperfusion therapy there was only week correlation between the Aldrich score and either the ischaemic area at risk or final infarct size, as measured by pretreatment and predischarge technetium $99 \mathrm{~m}\left({ }^{99 m} \mathrm{Tc}\right)$ sestamibi 
A

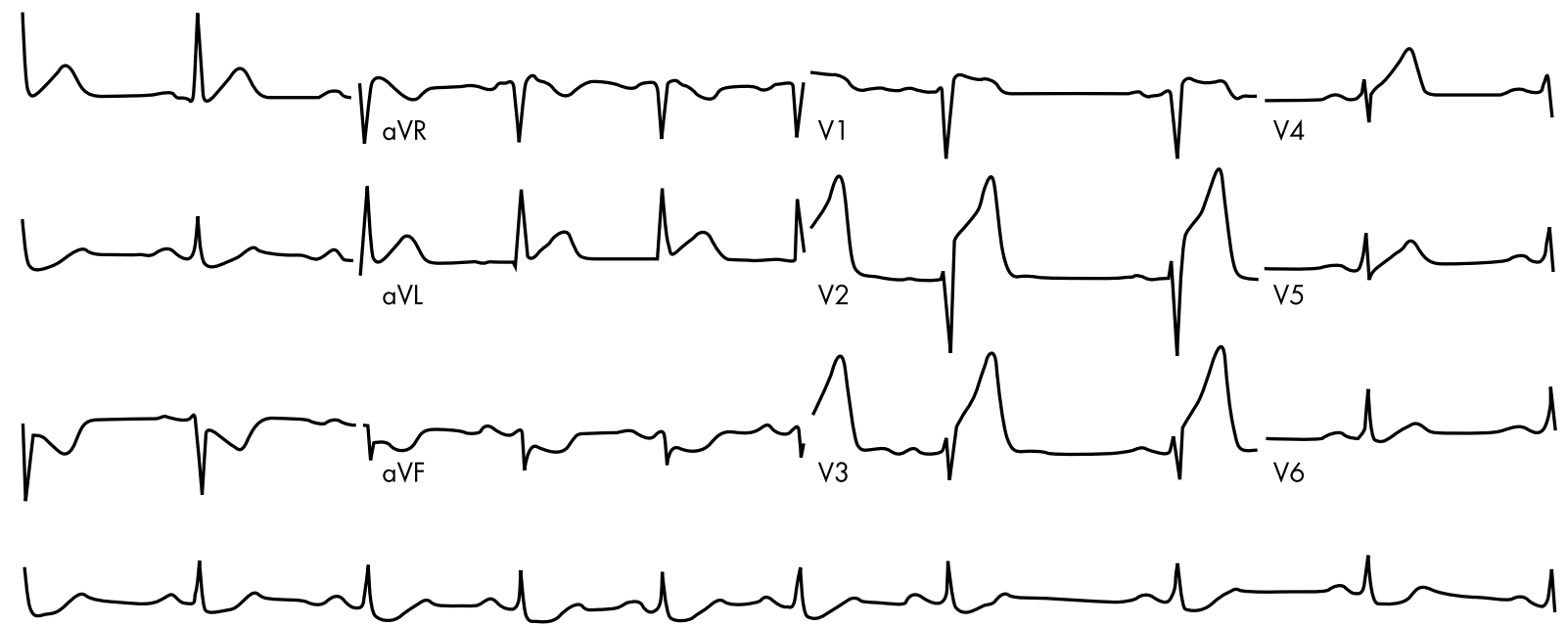

B
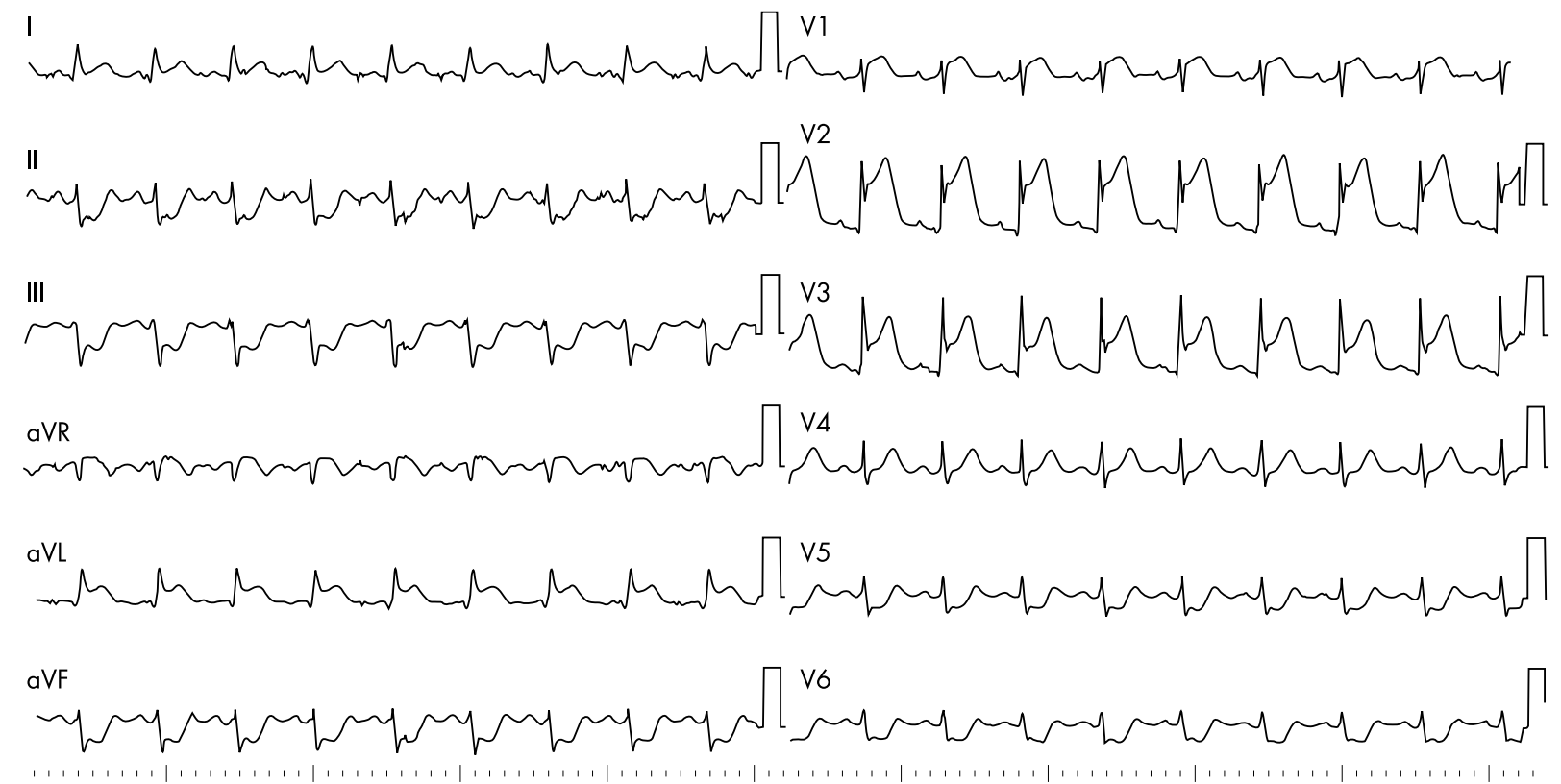

Figure 3 (A) A patient with anterior acute myocardial infarction with grade II ischaemia. There is ST elevation in aVL and V1-V4. The J/R ratio is less than 0.5 in aVL (a lead with qR configuration and ST elevation). The $S$ waves in leads V1-V4 are preserved. (B) A patient with anterior acute myocardial infarction and grade III ischaemia. There is ST elevation in leads I, aVL, VI-V3. There are no $S$ waves in leads V2-V3 (see text).

scans, respectively. ${ }^{37}$ The Aldrich formula was related more to the collateral score than to the ischaemic area at risk or final infarct size. ${ }^{37}$ Clemmensen et al reported a good correlation between the final Selvester score and the number of leads with ST elevation $(r=0.70)$ in anterior myocardial infarction. However there was only a weak correlation in inferior myocardial infarction. ${ }^{36}$ Neither the magnitude of ST segment elevation in all leads nor the number of leads with ST elevation correlated with the final Selvester score in inferior myocardial infarction. ${ }^{36}$ Clements et al also reported only a weak correlation between myocardial area at risk (as assessed by ${ }^{99 m}$ Tc sestamibi scan) and either the number of leads with ST deviation, total ST deviation, total ST elevation, or total ST depression. ${ }^{38}$ The myocardial area at risk correlated modestly $(r=0.58)$ with total ST deviation in anterior myocardial infarction, and with total ST depression normalised to the $\mathrm{R}$ wave $(r=0.70)$ in inferior myocardial infarction. However, because of large standard errors $(9 \%-15 \%$ of the left ventricle), these formulas for estimation of the myocardial area at risk cannot be used in the clinical setting for estimation of infarct size. ${ }^{38}$ Birnbaum et al showed that among patients with first anterior myocardial infarction, the correlation between either the number of leads with ST elevation or the sum of ST elevation and the extent and severity of regional left ventricular dysfunction (both at 90 minutes after initiation of thrombolytic therapy and at predischarge) was poor. ${ }^{41}$

All of these studies were based on the hypothesis that each lead represents the same amount of myocardium and that a similar size of ischaemic area in different locations of the left ventricle will result in similar magnitude of ST deviation in the same number of leads. However, the 12-lead ECG does not equally represent all myocardial regions. The inferior and anterior walls of the left ventricle are well represented, but the lateral, posterior, septal, and apical regions are relatively ECG silent. ${ }^{42} 43$ Moreover, ischaemia in opposed regions may attenuate or augment ST deviation. For example, in patients with ischaemia of the high anterolateral and inferior regions due to proximal occlusion of a dominant left circumflex 
A

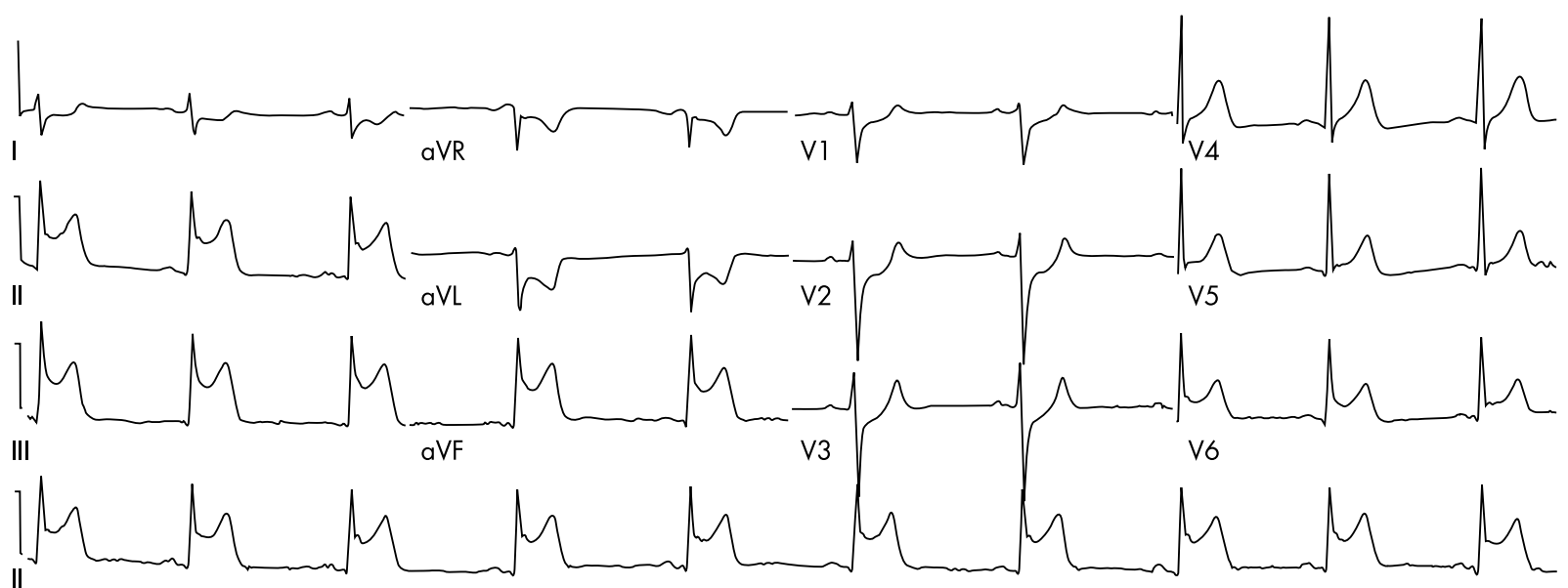

B
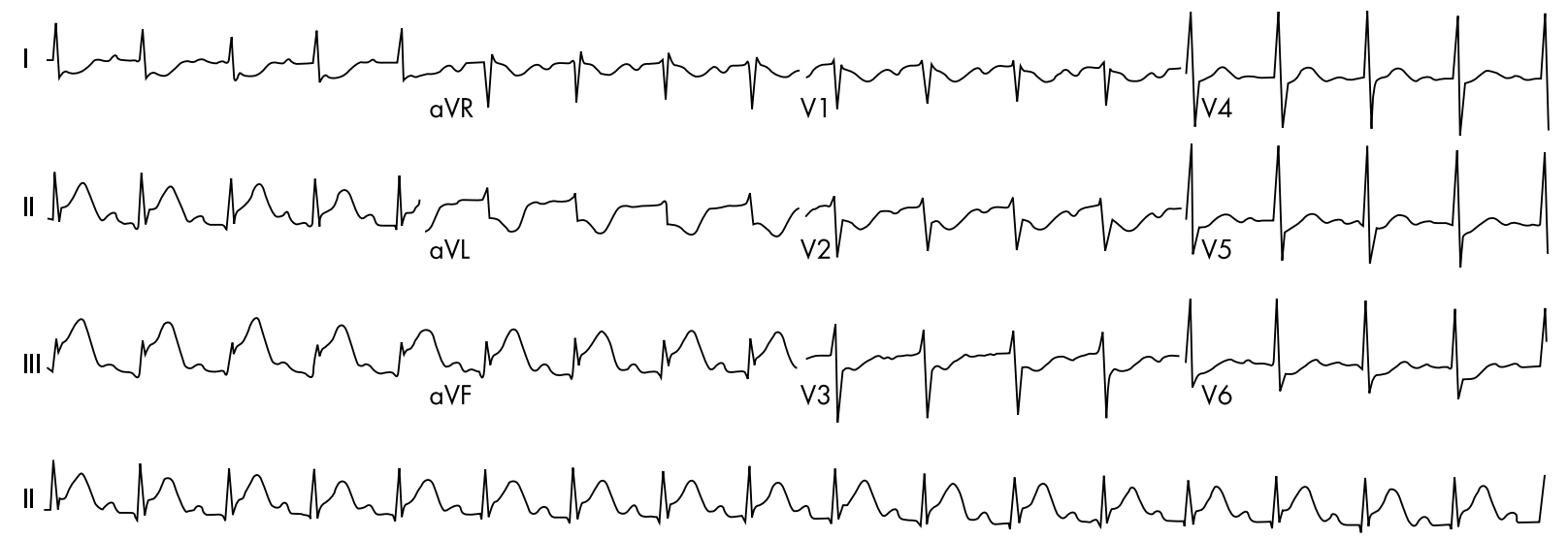

Figure 4 A patient with inferior acute myocardial infarction with grade II ischaemia. (A) There is ST elevation in II, III and aVF and V5-V6. The J/R ratio is less than 0.5 in all leads. (B) A patient with inferior acute myocardial infarction and grade III ischaemia. There is ST elevation in leads II, III, and aVF with a J/R ratio $>0.5$ in leads III and aVF (see text).

coronary artery occlusion, attenuation of ST deviation in leads I, aVL, and the inferior leads may occur, whereas subendocardial high anterolateral ischaemia may augment ST segment elevation in the inferior leads. Posterior myocardial infarction is commonly associated with ST depression in the precordial leads $\mathrm{Vl}-\mathrm{V} 3,{ }^{44}$ whereas right ventricular infarction may cause ST elevation in leads V1-V2. ${ }^{45}$

In concomitant right ventricle and posterior myocardial infarction, the opposing forces may neutralise each other and therefore, no ST deviation may occur in these leads. Because different leads represent different areas of the myocardium, a different coefficient should probably be used for each lead, and even for each type of infarction. To overcome the unequal presentation of the myocardium by the different leads, another technique has been suggested. ${ }^{46}{ }^{47}$ In this technique the maximal points of the Selvester score is given to each lead with ST elevation $\geqslant 100 \mu \mathrm{V}$. The sum of these initial scores is considered to represent the percentage of the left ventricle that is ischaemic. This method was compared to thallium-201 perfusion defect in 28 patients ( 10 patients on admission and 18 patients on day 5 after reperfusion therapy). ${ }^{46} \mathrm{~A}$ good correlation was found between this potential Selvester score and the extent of thallium-201 perfusion defect $(r=0.79$, $\mathrm{p}<0.005)$. Birnbaum et al found only a week correlation between the "maximal potential Selvester score" and the extent or severity of left ventricular dysfunction among patients with first anterior myocardial infarction who underwent left ventriculography at 90 minutes after initiation of thrombolytic therapy and at predischarge. ${ }^{41}$ The reproduc- ibility of this method should be verified in a larger cohort of patients, preferentially with assessment of the perfusion defect by ${ }^{99 m}$ Tc sestamibi imaging before reperfusion therapy is initiated.

Many variables such as width of the chest wall, the distance of the electrode from the ischaemic zone, the myocardial mass, and presence of "ischaemic preconditioning" and collateral circulation have a major influence on the absolute magnitude of ST deviation. Therefore, although in general patients with ST deviation in many leads, or high absolute sum of ST deviation have a larger infarction than patients with ST deviation in a small number of leads or low sum of ST deviation, ${ }^{3}{ }^{39}$ there are many exceptions. There are patients with a relatively large infarction who have only minor absolute ST deviation. Infarct size underestimation in these patients may lead to underutilisation of reperfusion therapy.

Another qualitative approach for predicting final infarct size by the admission ECG based on the grades of ischaemia has been reported by Birnbaum et al. ${ }^{244148}$ In the TIMI-4 trial, patients presenting with grade III ischaemia $(n=85)$ on admission had a larger infarct as assessed by creatine kinase release over 24 hours $(\mathrm{p}=0.023)$, and a larger predischarge ${ }^{99 \mathrm{~m}} \mathrm{Tc}$ sestamibi defect size $(\mathrm{p}=0.001) .{ }^{24}$ Comparing patients with first anterior myocardial infarction who were randomised to thrombolytic therapy or conservative treatment, it was found that final QRS Selvester score was lowered by thrombolytic therapy only among patients with grade II ischaemia on enrollment, but not grade III. ${ }^{25}$ Overall, final QRS Selvester score was higher for patients with grade III than 
grade II ischaemia on enrollment, both in those who received or did not receive thrombolytic therapy. Among patients with a first anterior myocardial infarction who participated in the GUSTO I angiographic substudy and underwent angiography both at 90 minutes after initiation of thrombolytic therapy and at predischarge, patients with grade II ischaemia on enrollment had larger left ventricular ejection fraction at 90 minutes than patients with grade III ischaemia. ${ }^{41}$ The difference in global left ventricular function was related mainly to the severity ( $\mathrm{SD} /$ chord) of regional dysfunction in the involved segments and less to the extent of involvement (size of the area at risk). ${ }^{41}$ At predischarge, The grade III group tended to have lower left ventricular ejection fraction and had significantly more chords with dysfunction and more severe regional dysfunction than the grade II group. The number of dysfunctional chords tended to decrease from 90 minutes to predischarge in the grade II group, whereas it tended to increase in the grade III group. This may reflect partial recovery from stunning at the predischarge ventriculography in the grade II group. ${ }^{41}$ There was no difference in the time to therapy or the success of thrombolysis between the grade II and III groups. Thus, it seems that the difference in infarct size between the grade II and grade III groups is explained by more severe ischaemia and not by larger ischaemic area at risk, longer ischaemia time or lower rates of successful reperfusion. ${ }^{41}$ Findings from the AMISTAD study confirmed this hypothesis. ${ }^{48}$ In this study, patients who receive thrombolytic therapy were randomised to pretreatment with intravenous adenosine or placebo. For placebo treated patients, the median pretreatment ${ }^{99 \mathrm{~m}} \mathrm{Tc}$ sestamibi single photon emission computed tomography (SPECT) perfusion defect (ischaemia area at risk) did not differ significantly between grade II and grade III patients, nor did median predischarge ${ }^{99 \mathrm{~m}}$ Tc sestamibi SPECT perfusion defect (infarct size), but the median infarction index (infarct size/ area at risk) was $66 \%$ compared with $90 \%(\mathrm{p}=0.006)$. For adenosine treated patients, the difference in the median infarction index $(31 \% v 67 \%, \mathrm{p}=0.23)$ between grade II and grade III patients did not reach statistical significance. Overall, infarct size was related to baseline ischaemia grade $(p=0.0121)$ and was reduced by adenosine treatment $(\mathrm{p}=0.045)$.

Most, but not all, studies have shown that as a group, patients with inferior acute myocardial infarction and ST depression in leads Vl-V3 have larger infarcts than their counterparts without ST depression, as evidenced by higher peak creatine kinase release; more extensive wall motion abnormalities; larger defect size by thallium-201, technetium99m, and positron emission tomography; and higher QRS scores of infarct size. ${ }^{74-63}$ In addition, ST elevation in V6 in patients with inferior acute myocardial infarction is also associated with larger myocardial infarction. ${ }^{64}$ Others have described that ST elevation in the posterior leads V7-V9 in patients with inferior acute myocardial infarction is associated with larger infarct size. ${ }^{65}$ However, it is unclear whether there is additive value for ST elevation in leads V7-V9 over V6 alone.

Thus currently, there is no accurate method for estimation of the area at risk by the admission ECG that can be used in the individual patient, although in general patients with ST deviation in many leads, or high absolute sum of ST deviation, have a larger myocardial infarction than patients with ST deviation in a small number of leads or low sum of ST deviation. The grades of ischaemia predict final infarct size, but not the size of the ischaemic area at risk.

\section{DIFFERENTIATION BETWEEN VIABLE AND NECROTIC MYOCARDIUM AT THE ISCHAEMIC AREA AT RISK}

Although with echocardiography old myocardial scars with thinning of the ventricular wall and dense echo reflections can be identified, none of the direct imaging modalities (contrast ventriculography and echocardiography) can differentiate between ischaemic but viable myocardium and myocardium that has already undergone irreversible necrosis in the acute stage of infarction.

Q waves were traditionally considered as a sign of myocardial necrosis. ${ }^{66}$ However, the mechanism and significance of Q waves that appears very early in the course of acute myocardial infarction ( $\leqslant 6$ hours from onset of symptoms) in leads with ST deviation are probably different. ${ }^{66-71}$ Fifty three percent of the patients with acute myocardial infarction admitted within one hour of onset of symptoms had abnormal $\mathrm{Q}$ waves on presentation, even before reperfusion therapy had been initiated. ${ }^{67}$ It has been suggested that $\mathrm{Q}$ waves that appear within six hours from onset of symptoms do not signify irreversible damage, and do not preclude myocardial salvage by thrombolytic therapy. ${ }^{68} 72$ Furthermore, Q waves that appear early in the course of acute ischaemia may be transient and disappear later. ${ }^{72-74}$ Several authors have found early Q waves to be associated with larger ischaemic zone and ultimate infarct size. ${ }^{67} 6875$ Such Q waves have been explained by a transient loss of electrophysiological function due to intense ischaemia ("myocardial concussion"). ${ }^{667276}$ In contrast, some investigators found that Q waves develop rapidly only after reperfusion. ${ }^{69-71} 77$ It has been suggested that the presence of Q waves may be masked by the injury current during ischaemia ${ }^{71}$ and they frequently can be seen only after resolution of the injury current. However, these changes may reflect reperfusion injury, interstitial oedema, or haemorrhage that may partially resolve later ${ }^{69}$ and may even result in enlargement of the final infarct size.

Thus, presence of abnormal Q waves in the leads with ST deviation is not a reliable sign of irreversible damage and does not preclude the benefits of reperfusion therapy. However, 90 minutes after thrombolytic therapy, TIMI flow grade III is achieved less often in patients with than without abnormal Q waves on presentation. ${ }^{78}$ Further studies are needed to find other ECG markers that will assist in differentiation between acutely ischaemic but viable from irreversible necrotic myocardium. Regardless of the underlying mechanism, presence of abnormal Q waves in the leads with ST elevation on the admission ECG is associated with larger final infarct size, and increased in-hospital mortality. ${ }^{79}$

Patients with grade III ischaemia on enrollment have larger final infarct size, ${ }^{248}$ but not larger initial ischaemic area at risk. ${ }^{41}{ }^{48}$ In addition, patients with grade III ischaemia are less likely to benefit from thrombolytic therapy than patients with grade II. ${ }^{25}$ However, distortion of the terminal portion of the QRS complex in leads with ST elevation is not a sign that irreversible damage had already occurred upon presentation, since the same ECG pattern is frequently detected in patients with Prinzmetal angina during ischaemic episodes that are not associated with significant myocardial damage.

Some patients with acute myocardial infarction present with ST elevation and negative T waves ( fig 5 ). Early inversion of the T waves, along with ST elevation resolution, is a sign of reperfusion, ${ }^{80}$ however, the significance of negative $\mathrm{T}$ waves in leads with ST elevation before reperfusion therapy is initiated is still unclear. Wong et al reported that 90 minutes after thrombolytic therapy, TIMI flow grade III was seen less often in patients presented with ST elevation and negative T waves than in those with positive T waves ${ }^{78}$ Herz et al reported that among patients treated 2-6 hours after onset of symptoms, those presented with inverted T waves in leads with ST elevation had higher in-hospital mortality than patients with positive T waves. ${ }^{81}$ In contrast, among patients treated within the first two hours of onset of symptoms, patients with negative T waves had no hospital mortality (0/52 patients), as compared to a $5.0 \%$ mortality rate in patients with positive T waves (36/ 726 patients; $p=0.19) .{ }^{81}$ Therefore, ST elevation with negative $\mathrm{T}$ waves, especially if it occurs in patients presenting more than two hours of onset of symptoms, might be a sign of a 
A
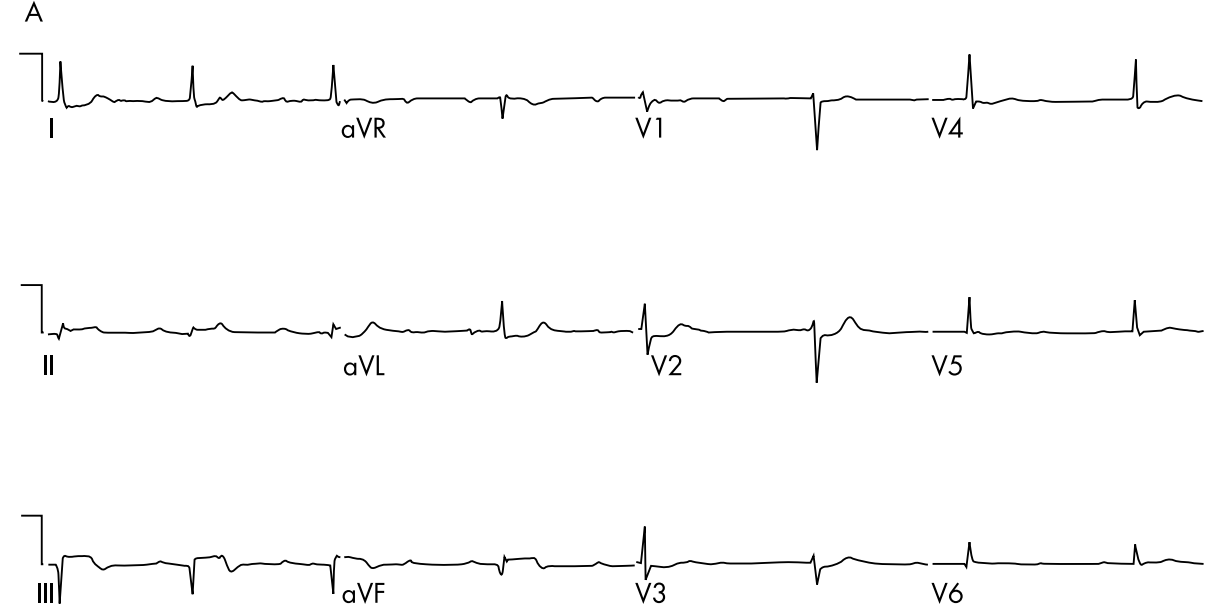

B

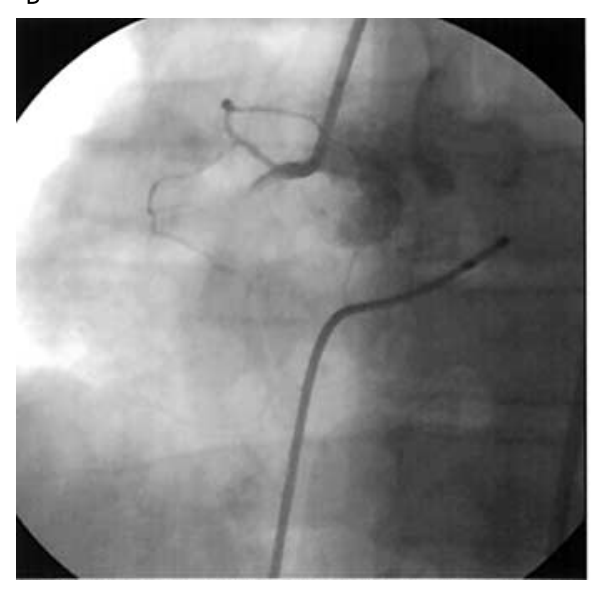

C

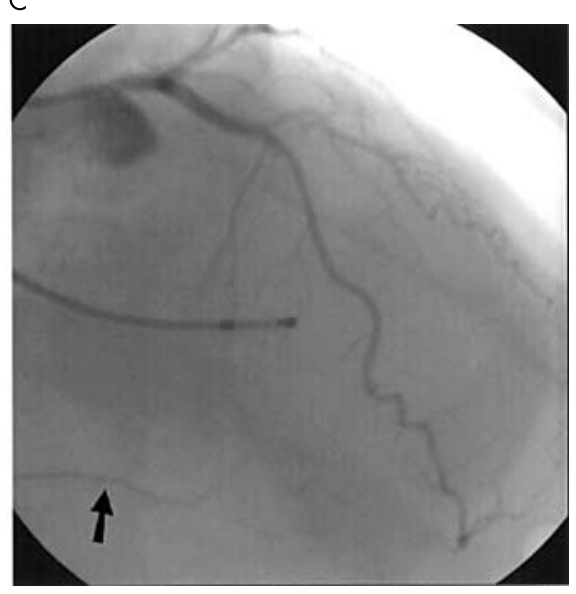

Figure 5 (A) An admission ECG of a patient with five hours of chest pain showing $Q$ waves, ST elevation, and negative $T$ waves in the inferior leads (II, III, and aVF). (B) Coronary angiography showed complete obstruction of the proximal portion of the right coronary artery. (C) The left coronary artery filled the right coronary artery by collaterals (arrow). more advanced stage of myocardial infarction with lesser chance of achieving successful reperfusion and higher mortality. It might be a sign that irreversible damage has already occurred. On the other hand, it might be that negative $\mathrm{T}$ waves in leads with ST elevation signify residual myocardial perfusion by either spontaneous recanalisation of the infarct related artery or by collaterals (as depicted in fig 5). It is plausible that collaterals develop especially in patients with pre-existing high grade stenosis and therefore, their recanalisation rate by thrombolytic therapy is low.

\section{EXPECTED RATE OF PROGRESSION OF MYOCARDIAL NECROSIS}

The severity of myocardial ischaemia or the expected rate of progression of myocardial necrosis cannot be estimated by left ventriculography or simple two dimensional echocardiography. It might be that with the new echocardiographic contrast agents, residual myocardial perfusion could be appreciated. However, slowing the progression of the wavefront of necrosis by metabolic factors including ischaemic preconditioning probably cannot be assessed.

The magnitude of ST elevation reflects mainly the severity of the subepicardial ischaemia. The standard surface 12-lead ECG is less sensitive to subendocardial ischaemia. Subendocardial ischaemia may cause either ST depression or no change in the ST segment at all. However, ST depression may also result from reciprocal changes in leads oriented away from the ischemic zone. ${ }^{82}$ Augmentation of the collateral flow ameliorates the magnitude of ST deviation during coronary balloon occlusion. ${ }^{83-85}$ Moreover, ischaemic preconditioning by preced- ing brief ischaemic episodes attenuates the magnitude of ST deviation. ${ }^{838687}$ However, data concerning the effects of myocardial preconditioning or presence of sufficient collateral circulation on the 12-lead ECG during acute myocardial infarction is spars. Collateral circulation reduces the severity of the subepicardial ischaemia, and hence, attenuates ST elevation. ${ }^{37}$ And indeed, Sagie et al showed that in patients with acute anterior myocardial infarction who had good collateral circulation, only T wave changes, without ST elevation (grade I ischaemia) were observed ${ }^{88}$ However, other cardiac and non-cardiac variables, such as presence of myocardial hypertrophy, the distance of the heart from the chest wall, the width of the chest wall, etc, also have influence on the magnitude of ST deviation. Therefore, the absolute magnitude of ST deviation can give only a rough estimation of the magnitude of myocardial protection or the "severity" of ischaemia.

Patients who develop a grade III of ischaemia (ST elevation with distortion of the terminal portion of the QRS) have more "severe" ischaemia, as is discussed above, or more rapid progression of the wavefront of necrosis. Birnbaum et al analysed 2603 patients with acute myocardial infarction who received intravenous thrombolytic therapy as part of the GUSTO-I protocol within six hours of the onset of symptoms. ${ }^{23}$ In-hospital mortality among patients treated within two hours from onset of symptoms was comparable between patients with grade III $(5.3 \%)$ and grade II $(4.2 \%$, $\mathrm{p}=0.61$ ). However, among patients treated more than two hours after onset of symptoms, mortality increased to $7.4 \%$ in patients with grade III of ischaemia whereas it did not change in patients with grade II of ischaemia (3.6\%, $p=0.0005)$. Thus, it might be that in patients with grade III of ischaemia, the 
beneficial effect of salvaging myocardium with reperfusion therapy is lost after two hours due to a more rapid rate of progression of the wavefront of necrosis. ${ }^{23}$ Findings from the AMISTAD study confirmed this hypothesis. ${ }^{48}$ When we plotted the ratio of the predischarge and pretreatment ${ }^{99 \mathrm{~m}} \mathrm{Tc}$ sestamibi SPECT myocardial perfusion defect as a function of the time elapsed from onset of symptoms to thrombolytic therapy, it became apparent that necrosis progressed more slowly in patients with grade II than grade III ischaemia. Adenosine pretreatment delayed the progression of necrosis, but did not alter the slope of the curve. The results of this study show that in patients with grade III ischaemia necrosis progresses rapidly and less myocardial salvage is expected, whereas in patients with grade II ischaemia there is more time for myocardial salvage. ${ }^{48}$ Patients with grade III ischaemia usually have larger infarct size because of more rapid rate of progression of irreversible damage, and not because they have initial larger ischaemic area at risk, longer ischaemic time, or lower rates of successful reperfusion. ${ }^{48}$

\section{PRESENCE OF OLD MYOCARDIAL INFARCTION OR FIBROSIS (MYOCARDIAL RESERVES)}

Global left ventricular function can be assessed by left ventriculography or two dimensional echocardiography. However, differentiation between old scar and acutely ischaemic zones is not always possible. Presence of abnormal Q waves in leads without ST elevation is suggestive of old myocardial infarction. Patients with inferior acute myocardial infarction and abnormal Q waves in the precordial leads have particularly bad prognosis. ${ }^{4}$ However, pathological $\mathrm{Q}$ waves in leads with ST elevation do not necessarily mean old myocardial infarction or completion of the present acute myocardial infarction. Abnormal Q waves were found in 53\% of 695 patients without a prior history of myocardial infarction admitted within one hour of onset of symptoms of acute myocardial infarction. ${ }^{67}$

\section{IDENTIFYING "ISCHAEMIA AT A DISTANCE"}

Patients with ST elevation in one territory often have ST depression in other territories. The additional ST deviation may represent ischaemia in a myocardial region other than the area of infarction or may represent pure reciprocal changes. There is abundant literature concerning the significance of different types of ST depression during acute myocardial infarction. ${ }^{82}$ Most of the common patterns of remote ST depression probably represent reciprocal changes and not "ischaemia at a distance". In anterior myocardial infarction, ST depression in the inferior leads is reciprocal to involvement of the basal anterolateral region, supplied by the first diagonal branch and represented by ST elevation in leads I and aVL. ${ }^{89-92}$ In patients with inferior myocardial infarction, ST depression in lead aVL is a pure reciprocal change and is found in almost all patients, ${ }^{93}$ and ST depression in leads V1-V3 probably do not represent "ischaemia at a distance", but rather reciprocal changes due to more posterior, inferoseptal, apical, or lateral left ventricular involvement. ${ }^{44} 495^{50} 57-59$ 94-98 In contrast, among patients with inferior myocardial infarction, ST depression in leads V4-V6 is associated with concomitant left anterior descending coronary artery stenosis or three vessel disease. $^{5799}$ Thus, presence of an atypical pattern of ST depression, and especially ST depression in leads V4-V6 in inferior myocardial infarction may signify "ischaemia at a distance". In special circumstances both types of ST depression may be present. In acute myocardial infarction due to occlusion of the first diagonal branch in addition to ST elevation in leads I, aVL and V2, there is usually reciprocal ST depression in the inferior leads. The reciprocal ST depression is associated with negative $\mathrm{T}$ wave. In contrast, in this type of myocardial infarction there is usually ST depression in leads
V3-V5, which signify subendocardial involvement. This type of ST depression is associated with tall peaked T waves. ${ }^{90}$

Boden et al reported that in patients with non-ST elevation acute myocardial infarction, isolated ST segment depression in leads Vl-V4 was more likely to be due to posterior involvement (reciprocal changes) when was associated with upright $\mathrm{T}$ waves, whereas it was due to anterior subendocardial ischaemia when the T waves were negative. ${ }^{100}$ However, we found that the polarity of the $\mathrm{T}$ waves in the precordial leads with ST depression cannot be used to differentiate between the two aetiologies of ST depression. In many patients with inferior acute myocardial infarction and ST depression in leads V1-V3, the T waves in these leads are negative initially (a reciprocal image of ST elevation with positive T waves in leads facing the infarct zone), and only later, the $\mathrm{T}$ waves become positive and the $\mathrm{R}$ wave amplitude increase (a reciprocal image of inversion of the T waves and development of Q waves in leads facing the infarction). ${ }^{101}$

\section{IDENTIFICATION OF THE EXACT SITE OF THE INFARCT RELATED ARTERY}

The admission ECG, by suggesting the location of the ischaemic area at risk, may assist in identification of the exact site of coronary artery occlusion. However, because there is variability in the coronary anatomy, in some instances there may be more than one possible explanation for a specific ECG pattern. Moreover, since the size and exact location of the vascular bed supplied by the occluded artery varies considerably, occlusion in the same site of a coronary artery in different patients may result in a different size and location of the ischaemic area at risk. Therefore, the ECG pattern may not be the same in all cases with similar coronary artery occlusion. In addition, presence of severe pre-existing narrowing in non-culprit coronary arteries may cause "ischaemia at a distance" that may alter the classical ECG picture. Much of the work that studied the correlation between various ECG patterns and the site of the culprit lesion included only patients with single vessel disease.

\section{ANTERIOR ACUTE MYOCARDIAL INFARCTION (BOX 2)}

\section{Classic ECG patterns}

Left anterior descending (LAD) coronary artery obstruction usually causes ST elevation in the precordial leads V1-V4. ${ }^{102}$ Aldrich et al reported similar findings showing the frequency of ST elevation in patients with acute myocardial infarction due to LAD occlusion to be in descending order: V2, V3, V4, V5, aVL, Vl, and V6. ${ }^{103}$

In relatively rare instances, ST elevation in leads VI-V4 signifies proximal right coronary artery occlusion with concomitant right ventricular infarction. ${ }^{45} 104105$ In Blanke and coworkers' analysis of 39 patients with acute myocardial infarction due to right coronary artery occlusion, the frequency of ST elevation in these four precordial leads was as follows: V1, two patients (5\%); V2 and V3, six patients ( $15 \%$ ); and V4, three patients $(8 \%){ }^{102}$ These investigators found no instances of ST elevation in leads Vl-V4 in the 25 patients with acute myocardial infarction due to left circumflex coronary artery occlusion. Right ventricular infarction that produces ST elevation in leads V1-V4 can be distinguished from anterior myocardial infarction by observing ST elevation in lead V1 greater than in lead V2, ST elevation in the right precordial leads V3R and V4R, ST depression in lead V6, and ST elevation in the inferior leads II, III, and aVF. ${ }^{104}{ }^{106}$ The magnitude of ST elevation in lead VI correlates better with the magnitude of ST elevation in lead V3R than with lead V2, suggesting that ST elevation in lead VI reflects the right ventricle more than the left ventricle. ${ }^{106}$ 
Box 2: Anterior wall acute myocardial infarction (left anterior descending (LAD) coronary artery)

1 Precordial leads

- ST elevation is usually present in V2-V4.

- ST elevation in V4-V6 without ST elevation in V1-V3 is usually due to left circumflex artery or distal diagonal branch occlusion.

- There are no data to support that ST elevation in V5 and V6 represents lateral or apical extension.

2 Leads I and aVL

- ST elevation in I and aVL signifies:

i. Occlusion of a short LAD coronary artery before the first diagonal branch (if there is ST elevation in V2-V4).

ii. Occlusion of the first diagonal branch (if associated with ST elevation in V2 and isoelectric ST or ST depression in V3-V6.

iii. Occlusion of the first marginal branch of the left circumflex artery (if there is ST depression in V2).

- ST depression in aVL signifies LAD artery occlusion distal to the first diagonal branch.

3 Leads II, III, and aVF

- ST depression in the inferior leads signifies:

i. Occlusion of a short LAD coronary artery before the first diagonal branch (if there is ST elevation in V2-V4).

ii. Occlusion of the first diagonal branch (if associated with ST elevation in V2 and isoelectric ST or ST depression in V3-V6.

- ST elevation in the inferior leads signifies occlusion of a long LAD artery (that wraps the cardiac apex) distal to the first diagonal branch.

4 Lead aVR

- ST elevation in aVR signifies left anterior artery occlusion proximal to the first septal branch.

5 Right bundle branch block (new)

- Signifies left anterior artery occlusion proximal to the first septal branch.

\section{Diagnosis of anterior infarction extending to contiguous myocardial zones}

Anterosuperior myocardial zone

The high anterolateral wall at the base of the left ventricle receives its coronary blood flow from the first diagonal branch of the LAD artery, the first obtuse marginal branch of the left circumflex artery, or occasionally, from the ramus intermedius artery. ${ }^{107}$ The ECG lead that most directly faces this anterosuperior myocardial zone is lead aVL. ${ }^{107}{ }^{108}$ In acute anterior myocardial infarction, ST elevation in lead I, and particularly in lead $\mathrm{aVL}$, signifies a LAD artery occlusion proximal to the first diagonal branch. ${ }^{92} 108$ In contrast, ST depression in lead aVL during acute anterior myocardial infarction signifies a LAD artery occlusion distal to the first diagonal branch. ${ }^{109}$ While ST elevation in lead aVL is a very specific sign of proximal LAD occlusion, it has a relatively low sensitivity for this diagnosis. Sasaki and coworkers helped to explain the absence of ST elevation in aVL in some patients with proximal LAD occlusion. ${ }^{110}$ These investigators noted that patients with a long LAD artery that wraps around the cardiac apex have concomitant injury to the inferiorapical and anterosuperior walls of the left ventricle. When this happens, no ST elevation may be seen in either anterosuperior leads (that is, I, aVL) or inferior leads (that is, II, III, aVF) because the opposing forces cancel each other out.

Isolated occlusion of the first diagonal branch may also cause ST elevation in lead aVL. ${ }^{90}{ }^{108}$ However, the ECG can be useful in distinguishing isolated diagonal branch occlusion from a LAD artery occlusion proximal to the first diagonal branch. Occlusion of the diagonal branch typically results in ST elevation in leads I, aVL, and V2 with ST segments in leads
V3 and V4 either isoelectric or depressed.$^{90}{ }^{107}$ In contrast, a LAD artery occlusion proximal to the first diagonal branch results in ST elevation extending beyond lead V2-V3 and occasionally, to V4-V6. ${ }^{90}{ }^{107}$ In addition, when ST elevation in leads I and aVL are due to occlusion of the left circumflex artery, reciprocal ST depression is usually observed in lead V2 because the vascular bed supplied by the left circumflex artery extends more posteriorly. ${ }^{107}$

ST depression in the "inferior" leads II, III, and aVF during acute anterior myocardial infarction indicates injury to the high anterolateral wall and does not signify inferior wall ischaemia. ${ }^{91}{ }^{111}$ Several investigators found such reciprocal ST depression in the inferior leads to indicate a LAD artery occlusion proximal to the first diagonal branch. ${ }^{89} 92109$ Moreover, Haraphongse and coworkers found that patients with acute anterior myocardial infarction who had ST depression in the inferior leads had worse left ventricular function and a more complicated clinical course than did patients without such reciprocal ST changes. ${ }^{111}$ However, in patients with a long LAD artery that wraps around the cardiac apex, proximal LAD artery occlusion may not produce reciprocal ST depression in the inferior leads because of extension of the infarction to the inferoapical wall. ${ }^{110}$

Several ECG criteria have been reported to indicate a LAD artery occlusion proximal to the first septal perforator branch: (1) ST elevation in lead aVR $(p=0.000)$; (2) right bundle branch block $(\mathrm{p}=0.004)$; (3) ST depression in lead V5 $(p=0.009)$; and (4) ST elevation in lead Vl of greater than 2.5 $\mathrm{mm}(\mathrm{p}=0.011) \cdot{ }^{109}$ However, Birnbaum et al did not find an association between ST elevation in lead VI and LAD artery occlusion proximal to the first septal branch. ${ }^{112}$ Criteria reported to indicate a LAD artery occlusion distal to the first septal perforator branch include abnormal Q waves in leads V4-V6. ${ }^{109}$

\section{Lateral and apical myocardial zones}

The vast majority of patients (93\%) with an acute anterior myocardial infarction due to LAD artery occlusion have an "anteroseptal" pattern (ST elevation in leads V1-V3). ${ }^{102}{ }^{103}$ In contrast, isolated ST elevation in leads V4-V6, without ST elevation in leads V1-V3 is usually due to an occlusion of the left circumflex artery or distal diagonal branch rather than the main LAD artery. It is plausible that in patients with "extensive anterior" myocardial infarction (ST elevation in leads V1-V6), the injury extends to the distal anterolateral wall and cardiac apex due to a long LAD artery and/or prominent diagonal branches, whereas patients with an "anteroseptal" pattern (ST elevation confined to leads V1-V3) have a short LAD artery or large obtuse marginal branches or ramus intermediate branch that supply these anterolateral and apical zones. However, there have been no investigations to determine whether there are differences in coronary anatomy between patients with an "anteroseptal" versus an "extensive anterior" myocardial infarction ECG pattern. Recently, using transthoracic echocardiography, Porter and coworkers found no difference in regional wall motion abnormalities in the lateral and apical segments in patients with first acute anterior myocardial infarction, with or without ST elevation in leads V5 and V6. ${ }^{113}$

\section{Inferior myocardial zone}

During acute anterior myocardial infarction, injury may extend to the inferior wall, as evidenced by ST elevation in leads II, III, and aVF, if the LAD artery wraps around the cardiac apex..$^{102} 114115$ As previously mentioned, however, anterior myocardial infarction that is caused by a LAD artery occlusion proximal to the first diagonal branch does not manifest such an "anterior and inferior" injury pattern because of cancellation of opposing vectors. ${ }^{11015}$ In theory, occlusion of a LAD artery that supplies collateral blood flow to an obstructed right 
Table 1 Common ECG features distinguishing the culprit artery in acute inferior wall myocardial infarction

\begin{tabular}{|c|c|c|c|c|c|}
\hline \multicolumn{3}{|c|}{ Right coronary artery occlusion } & \multicolumn{3}{|l|}{ Left circumflex artery occlusion } \\
\hline Criterion & $\begin{array}{l}\text { Sensitivity } \\
(\%)\end{array}$ & $\begin{array}{l}\text { Specificity } \\
(\%)\end{array}$ & Criterion & $\begin{array}{l}\text { Sensitivity } \\
(\%)\end{array}$ & $\begin{array}{l}\text { Specificity } \\
(\%)\end{array}$ \\
\hline 1. $S T \uparrow V 3 R, V 4 R$ & 100 & 87 & 1. No ST $\downarrow$ aVL & 80 & 93 \\
\hline \multicolumn{6}{|c|}{ 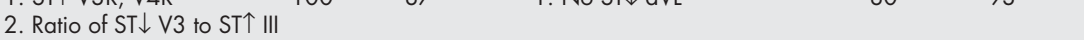 } \\
\hline$<0.5=$ proximal $R C A$ & 91 & 91 & 2. Ratio of ST $\downarrow$ V3 to $S T \uparrow I I I>1.2$ & 84 & 95 \\
\hline $0.5-1.2=$ distal RCA & 84 & 93 & & & \\
\hline 3. $S: R$ wave ratio $a V L>3$ & 76 & 88 & & & \\
\hline 4. ST $\uparrow$ III > II & 88 & 94 & 3. $S: R$ wave ratio $a V L \leqslant 3$ & 88 & 76 \\
\hline 5. ST $\downarrow a V L>1$ & 80 & 94 & & & \\
\hline
\end{tabular}

coronary or left circumflex artery might produce a similar "anterior and inferior" pattern; however, Tamura et al did not observe such a pattern in the 12 patients they studied with this type of ECG. ${ }^{115}$

\section{ACUTE INFERIOR MYOCARDIAL INFARCTION Classic ECG patterns}

In inferior acute myocardial infarction, the leads showing the greatest magnitude of ST elevation are, in descending order: leads III, aVF, and II. The vast majority $(80 \%-90 \%)$ of patients with ST elevation in these "inferior" leads have an occlusion of the right coronary artery; however, an occlusion of the left circumflex artery can produce a similar ECG pattern. ${ }^{116}$ In addition to ST elevation in the inferior leads II, III, and aVF, reciprocal ST depression in lead aVL is seen in almost all patients with acute inferior myocardial infarction. ${ }^{93}$

\section{ECG distinction between right coronary artery versus left circumflex artery related acute inferior myocardial infarction (table 1)}

ECG confirmation of the infarct related artery during acute inferior myocardial infarction may be particularly valuable when coronary angiography indicates lesions in both the right and left circumflex coronary arteries. Several investigators have studied the ECG differences between acute inferior myocardial infarction due to right coronary artery versus left circumflex artery occlusion. ${ }^{16-122}$

\section{Criteria in the precordial leads}

Because the right ventricular branch originates from the proximal right coronary artery, criteria for right ventricular infarction, especially ST elevation in leads V3R and V4R, provide compelling evidence that the infarct related artery in acute inferior myocardial infarction is the right coronary artery. In contrast, Kontos et al reported that left circumflex artery related inferior myocardial infarction was suggested by observing reciprocal ST depression in leads V1 and V2. ${ }^{117}$ However, when Birnbaum and colleagues compared patients with inferior myocardial infarction due to mid or distal right coronary artery versus left circumflex artery occlusion, they found no difference in the frequency of ST depression in leads V1-V3. ${ }^{7}$ ST depression is absent in leads V1-V3 only during proximal right coronary artery occlusion because the resultant right ventricular injury pattern cancels out such reciprocal ST changes. $^{7}$

Some investigators have reported a higher frequency of ST elevation in leads V4-V6 in patients with left circumflex related acute inferior myocardial infarction. ${ }^{117}{ }^{118}$ However, Hasdai et al found little difference in the frequency of ST elevation in leads V4-V6 between patients with left circumflex versus right coronary artery related inferior infarction. ${ }^{120}$ These investigators explain that because the vast majority of acute inferior myocardial infarctions are due to right coronary artery occlusions, the positive predictive value of ST elevation in leads V5 or V6 for a left circumflex related infarction is only $59 \% .{ }^{120}$

Kosuge et al reported that the magnitude of ST depression in lead V3 relative to the ST elevation in lead III (V3:III ratio) was useful in distinguishing the culprit artery in acute inferior myocardial infarction. ${ }^{121}$ These investigators found that a V3:III ratio $<0.5$ indicated a proximal right coronary artery occlusion; a V3:III ratio of 0.5 to 1.2 indicated a distal right coronary artery occlusion; and, a V3:III ratio of $>1.2$ indicated a left circumflex artery occlusion. ${ }^{121}$

\section{Criteria in the limb leads}

ECG criteria in the limb leads have also been found to be useful in distinguishing right coronary artery versus left circumflex artery occlusion in acute inferior myocardial infarction. For example, greater ST elevation in lead III than in lead II has been shown to indicate right coronary artery related infarction. ${ }^{119}{ }^{123}$ Additional limb lead criteria involve careful analysis of leads I and aVL. Patients with left circumflex artery related myocardial infarction less frequently show reciprocal ST depression in lead aVL and more often show an isoelectric or a raised ST segment in leads I and aVL compared to patients with right coronary artery related inferior infarction. ${ }^{11719}$ Hasdai et al reported that such absence of reciprocal ST depression in lead aVL indicates injury of the anterosuperior base of the heart typically caused by left circumflex artery occlusion proximal to the first obtuse marginal branch. ${ }^{120}$ These investigators found absence of reciprocal ST depression in lead aVL in $86 \%$ of patients with proximal left circumflex related inferior myocardial infarction but in none of the patients with right coronary or distal left circumflex related infarctions $(\mathrm{p}=0.0001) .{ }^{120}$

An additional criterion for identifying the culprit artery in acute inferior myocardial infarction is the magnitude of ST depression in lead aVL compared to lead I. ${ }^{119}$ Greater reciprocal ST depression in lead aVL than in lead I suggests a right coronary artery related inferior infarction. ${ }^{119}$ A likely explanation for this phenomenon is that injury of the high posterolateral region caused by left circumflex artery occlusion attenuates ST depression in lead aVL more than in lead I, which has a less superior orientation.

A final criterion in lead aVL to distinguish the culprit artery in acute inferior myocardial infarction relates to the amplitude of the respective $\mathrm{R}$ and $\mathrm{S}$ waves in this lead. ${ }^{122}$ In general in the initial stages, leads facing an infarcted wall with ST elevation tend to show QRS changes as well, including an increase in R wave amplitude and a decrease in $\mathrm{S}$ wave amplitude. ${ }^{124}$ Therefore, in inferior myocardial infarction, the opposite pattern (that is, decrease in $\mathrm{R}$ wave and increase in $\mathrm{S}$ wave) would be expected in lead aVL, if there is no involvement of the high 


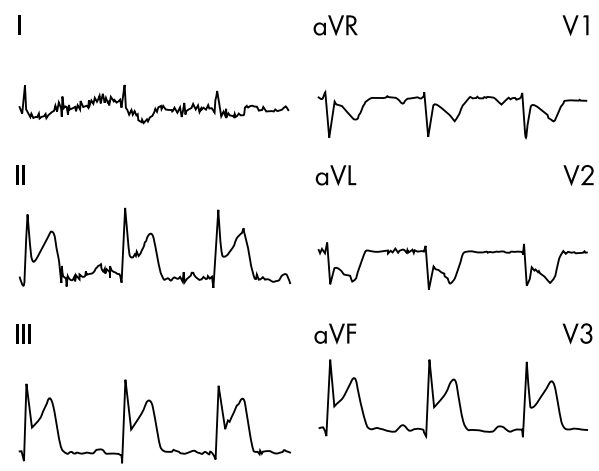

I

B

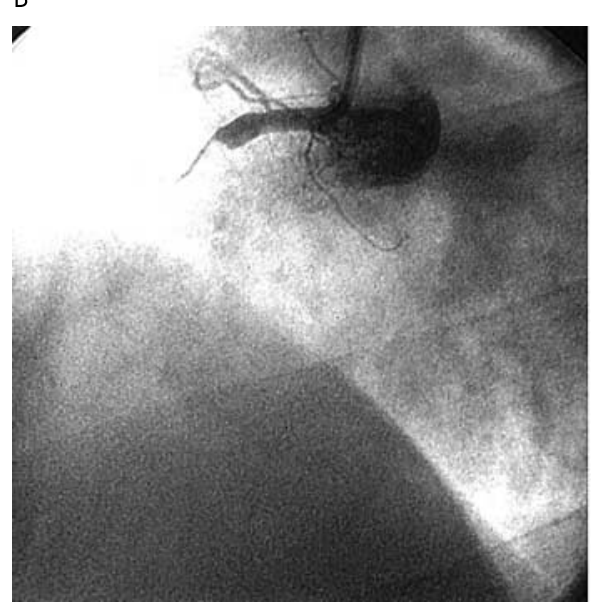

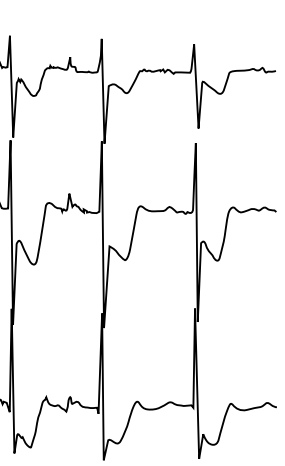

C

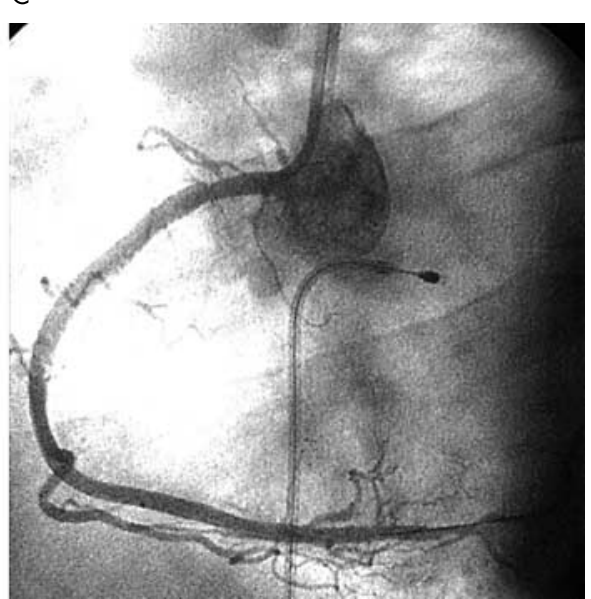

Figure 6 ECG of a patient with acute inferior myocardial infarction. (A) There is ST elevation in leads II, III, aVF, V5, and V6, and ST depression in I, aVL, V1-V3. Several criteria implicate the right coronary artery as the infarct related artery including: (1) greater ST elevation in lead III than in II, (2) greater ST depression in aVL than I, and (3) a $\mathrm{S}: \mathrm{R}$ ratio $>3$ in $\mathrm{VVL}$. There is also evidence for a larger than expected inferior infarction with extension to the lateral aspect of the cardiac apex (ST elevation in V5 and V6) and injury to the posterior wall (ST depression in leads $\mathrm{V} 1-\mathrm{V} 3$ ). (B) Coronary angiography confirms complete occlusion of the right coronary artery. (C) After primary angioplasty, a dominant right coronary artery with a large posterolateral branch is revealed, which is in agreement with ECG findings of posterior and lateral wall infarct extension. posterolateral region (right coronary artery infarction). In contrast, if there is concomitant involvement of the high posterolateral segments (as expected in left circumflex infarction), these reciprocal changes in the QRS may not be apparent. Indeed, Assali et al found that a decrease in $\mathrm{R}$ wave amplitude and an increase in $S$ wave amplitude with a $S: R$ ratio of $>3$ predicted right coronary artery occlusion whereas a $\mathrm{S}: \mathrm{R}$ ratio $\leqslant 3$ predicted left circumflex artery occlusion. ${ }^{122}$

A summary of the criteria to distinguish the culprit artery in inferior acute myocardial infarction is provided in box 2 and an example of the criteria is shown in fig 6.

\section{Diagnosis of inferior infarction extending to contiguous myocardial zones}

Right ventricular myocardial zone

When right ventricular infarction occurs, it almost always occurs in the setting of inferior acute myocardial infarction. Although isolated right ventricular infarction has been reported, it is rare and occurs most often in patients with right ventricular hypertrophy. ${ }^{125}$ Multiple investigators have found that ST elevation in lead V4R is diagnostic of right ventricular infarction with sensitivities and specificities well over $90 \%{ }^{116}{ }^{126}{ }^{127}$ It is important to point out that ST elevation in the right precordial leads (for example, V4R) is most prominent in the early hours of inferior acute myocardial infarction and rapidly dissipates thereafter. Hence, the window of opportunity to diagnose right ventricular infarction using the ECG is limited and right precordial leads should be recorded immediately when a patient with ST elevation in the inferior leads presents to the emergency department.

As aforementioned, ST elevation in leads V1-V3 in a patient with acute inferior myocardial infarction is a manifestation of associated right ventricular infarction due to a proximal right coronary artery occlusion. ${ }^{4104}{ }^{105}$ Lopez-Sendon et al reported that the criterion of ST elevation in lead V4R greater than ST elevation in any of leads Vl-V3 was a very specific sign of right ventricular infarction (specificity, 100\%). ${ }^{128}$ However, this criterion was less sensitive (sensitivity, 78.6\%) than ST elevation in V4R alone. ${ }^{128}$

\section{Lateral apical myocardial zone}

In patients with acute inferior myocardial infarction, ST elevation in leads V5 and V6 is thought to indicate extension of the infarct to the lateral aspect of the cardiac apex; however, there is as yet no direct evidence for this. ${ }^{129}$ The cause of such an extension may be occlusion of either the left circumflex or a right coronary artery with a posterior descending or posterolateral branch that extends to the lateral apical zone. ${ }^{129}$ Tsuka and coworkers found that ST elevation in lead V6 during inferior acute myocardial infarction was associated with a larger infarct size, a greater frequency of major cardiac arrhythmias, and a higher incidence of pericarditis during the patient's hospital course. ${ }^{64}$

\section{Posterior myocardial zone}

In patients with acute inferior myocardial infarction, ST depression in leads Vl-V3 has been shown by numerous investigators to indicate a larger infarction with extension of the injury to the posterolateral and/or the inferoseptal wall. ${ }^{44} 5054$ 57-59 95 97 130-135 Such ST depression in these "anterior" leads during acute inferior myocardial infarction is a reciprocal change and does not indicate concomitant LAD coronary artery disease. ${ }^{799}$ It is seen in both right coronary artery and left circumflex related inferior infarctions. ${ }^{43}{ }^{136}$ However, in inferior myocardial infarction due to proximal right coronary 
artery occlusion with concomitant right ventricular infarction, posterior wall injury may be masked because the two opposed electrical vectors may cancel each other (that is, ST elevation in leads V1-V3 with right ventricular infarction and reciprocal ST depression in these same leads with concurrent posterior infarction) ${ }^{94}$

A more direct sign of posterior wall injury is ST elevation in leads V7-V9. ${ }^{65}{ }^{137-139}$ However, waveform amplitudes in these posterior leads are lower than in standard precordial leads, presumably because the heart is situated more anteriorly in the chest and thus, is a greater distance from posteriorly placed electrodes. There is preliminary evidence that ST elevation of $0.5 \mathrm{~mm}$ should be considered a sign of injury when analysing the posterior leads. ${ }^{140}$ Isolated ST elevation in leads V7-V9 without ST elevation in the inferior leads occurs in only $4 \%$ of patients with acute myocardial infarction, ${ }^{139}$ and is usually due to left circumflex coronary artery occlusion. ${ }^{137}$ In patients with acute inferior myocardial infarction, ST elevation in leads V7-V9 is associated with a higher incidence of reinfarction, heart failure, and death..$^{65}$

\section{"Ischaemia at a distance" in acute inferior wall myocardial infarction}

Patients with ST elevation in one myocardial zone often have concurrent ST depression in other myocardial zones. Such ST depression may represent pure "mirror image" reciprocal changes or may be indicative of acute ischaemia due to coronary artery disease in non-infarct related arteries ("ischaemia at a distance"). Most of the ST depression patterns seen during ST elevation myocardial infarction represent reciprocal changes rather than ischaemia at a distance. ${ }^{82}$ However, one ECG pattern, ST depression in leads V5 and V6 in acute inferior myocardial infarction, does signify concomitant coronary artery disease of the LAD vessel with acute ischaemia in a myocardial zone remote from the infarct zone. ${ }^{599} 141$ Patients with maximal ST depression in leads V4-V6 during acute inferior myocardial infarction have higher morbidity and mortality compared with patients without precordial ST depression or with maximal depression in leads VI-V3. ${ }^{6}$ Likewise, patients with maximal ST depression in leads V4-V6 undergo multivessel revascularisation (multivessel percutaneous coronary interventions or coronary artery bypass surgery) more often than do patients without such an ECG pattern. ${ }^{141}$

\section{DISCUSSION}

The question might be posed, "Is it necessary for emergency physicians to have in-depth knowledge in assessing the ECG in patients with ST elevation myocardial infarction?" Three ECG assessments presented in this review that are especially relevant to the emergency department setting are the identification of: (1) right ventricular infarction accompanying acute inferior myocardial infarction, (2) a very proximal LAD coronary artery occlusion in anterior myocardial infarction, and (3) patients at higher risk, grade III of ischaemia or ST depression in V4-V6, indicating multivessel disease in inferior acute myocardial infarction. Moreover, it is crucial to recognise cases in which opposing ECG vectors cancel each other and result in attenuation of the ischaemic changes, such as occlusion of a proximal LAD that wraps the cardiac apex or a proximal dominant left circumflex artery. In terms of the first assessment, the opportunity to diagnose right ventricular infarction using the ECG is greatest in the emergency department because ST elevation in the right precordial leads resolves quickly. For example, in patients diagnosed with right ventricular infarction in the emergency department, it is not unusual to see isoelectric ST segments in the right precordial leads, despite continued ST elevation in the inferior leads, II, III, and aVF, by the time the patient is admitted to a hospital unit. Hence, emergency physicians should make certain that all patients with acute inferior myocardial infarction have a second ECG recorded with right ventricular leads. If ST segment elevation of $1 \mathrm{~mm}$ is observed in lead V4R, the diagnosis of right ventricular infarction can be made and no further right precordial ECGs need to be recorded. The reason it is important to identify patients with right ventricular infarction is that hypotension in these patients is usually caused by inadequate filling of the left ventricle by the poorly contracting right ventricle. Therefore, treatment should be aimed at augmenting ventricular filling by volume expansion and avoiding diuretics and nitrates. Such treatment is contrary to the treatment of cardiogenic shock due to pump failure, as occurs with large infarctions of the left ventricle.

Another ECG assessment of importance to emergency physicians is the identification of a very proximal LAD coronary artery occlusion in acute anterior myocardial infarction. If the infarct site is proximal to the first diagonal branch of the LAD artery, a large portion of the left ventricle is at risk for infarction including the anteroseptal, anterosuperior, anterolateral, and apical regions. Such high risk patients may require urgent transfer to the cardiac catheterisation laboratory for primary percutaneous coronary intervention or immediate treatment in the emergency department with a thrombolytic agent. Patients with grade III ischaemia on the admission ECG have a higher mortality ${ }^{22-24} 4^{142} 143$ and reinfarction rate. ${ }^{142}{ }^{144}$ Retrospective analysis of the GUSTO IIb trial patients revealed that grade III ischaemia was associated with higher mortality both in the primary angioplasty group and in the thrombolysis group. ${ }^{142}$ In the grade II group, in-hospital mortality was similar in the thrombolysis and angioplasty subgroups $(3.2 \%$ and $3.3 \%, p=0.941)$. In patients with grade III, in-hospital mortality was $6.4 \%$ and $7.3 \%$, respectively $(p=0.762)$. The odds ratio for the grade III group for death with thrombolysis was 2.06 (95\% confidence interval (CI) 0.82 to 5.19; p = $0.125)$; the odds ratio for primary angioplasty was 2.30 (95\% CI 0.93 to $5.66 ; \mathrm{p}=0.07$ ). In the thrombolysis group, reinfarction occurred in $3.3 \%$ and $6.5 \%$ of the grade II and grade III subgroups $(p=0.137)$. In the angioplasty group, reinfarction occurred in $1.3 \%$ and $4.4 \%$, respectively $(\mathrm{p}=0.239)$. Thus, primary angioplasty reduced the risk of reinfarction in grade III as well as grade II patients, but did not reduce mortality. Currently we are comparing the clinical outcome of patients with acute myocardial infarction treated with primary angioplasty or thrombolytic therapy both in patients treated in hospitals with and without on site intervention facilities (the DINAMI 2 trial). The decision to treat patients with early reperfusion therapy is the domain of emergency physicians, who therefore play a critical part in salvaging myocardium in patients with potentially extensive myocardial infarction.

There are two additional reasons for emergency physicians to become more skilled in the ECG assessment of patients with acute coronary syndromes. First, there is a growing trend for 12-lead ECGs to be recorded in the field by paramedics. Cellular telephone transmission of ECGs recorded in the field to the target emergency department is currently feasible. It is conceivable that emergency physicians will be involved in triaging patients in the prehospital phase to hospitals offering primary percutaneous coronary intervention, which is now recognised to be a superior reperfusion strategy, compared to thrombolytic therapy. ${ }^{145}$ Second, there is a growing trend for patients to be held for long periods of time in the emergency department because of a shortage of acute care hospital beds. Thus, the emergency department is becoming a critical care unit in many hospitals, requiring emergency physicians to be astute in the assessment of serial ECGs in the management of patients with acute coronary syndromes.

\section{CONCLUSION}

The admission ECG in patients with ST elevation acute myocardial infarction is valuable not only for determining who should and should not receive early reperfusion 
treatment, but also for providing information regarding the location and extent of acute myocardial injury. By reflecting the pathophysiology of the myocardium during acute ischaemia, the ECG conveys information unique from that of coronary angiography and provides important information to guide clinical decision-making.

\section{Authors' affiliations}

Y Birnbaum, University of Texas Medical Branch, Galveston, Texas

B J Drew, University of California, San Francisco

\section{REFERENCES}

Ryan TJ, Anderson JL, Antman EM, et al. ACC/AHA guidelines for the management of patients with acute myocardial infarction: executive summary. A report of the American College of Cardiology/American Heart Association Task Force on practice guidelines (Committee on management of acute myocardial infarction). Circulation 1996;94:2341-50.

2 Bertrand ME, Simoons ML, Fox KA, et al. Management of acute coronary syndromes: acute coronary syndromes without persistent ST segment elevation. Recommendations of the Task Force of the European Society of Cardiology. Eur Heart J 2000;21:1406-32.

3 Arnold AER, Simoons ML. "Expected infarct size without thrombolysis", a concept that predicts immediate and long-term benefit from thrombolysis for evolving myocardial infarction. Eur Heart $\rfloor$ 1997: 18:1736-48.

4 Moshkovitz Y, Sclarovsky S, Behar S, et al. Infarct site-related mortality in patients with recurrent myocardial infarction. SPRINT Study Group. Am J Med 1993;94:388-94.

5 Strasberg B, Pinchas A, Barbash GI, et al. Importance of reciprocal ST segment depression in leads V5 and V6 as an indicator of disease of the left anterior descending coronary arery in acute inferior wall myocardial infarction. Br Heart J 1990;63:339-41.

6 Birnbaum Y, Sclarovsky S, Strasberg B. Critical left main stenosis (letter). Am Heart J 1994; 127: 1662-3.

7 Birnbaum Y, Wagner GS, Barbash Gl, et al. Correlation of angiographic findings and right (V1 to V3) versus left (V4 to V6) precordial ST-segment depression in inferior wall acute myocardia infarction. Am J Cardiol 1999:83:143-8.

8 Habib GB, Heibig J, Forman SA, et al. Influence of coronary collateral vessels on myocardial infarct size in humans. Results of Phase I Thrombolysis in Myocardial Infarction (TIMI) Trial. Circulation 1991:83:739-46.

9 Haider AW, Andreotti F, Hackett DR, et al. Early spontaneous intermittent myocardial reperfusion during acute myocardial infarction is associated with augmented thrombogenic activity and less myocardial damage. J Am Coll Cardiol 1995;26:662-7.

10 Kloner RA, Yellon D. Does ischemic preconditioning occur in patients? J Am Coll Cardiol 1994; 24:1133-42.

11 Sclarovsky S, Mager A, Kusniec J, et al. Electrocardiographic classification of acute myocardial ischemia. Isr J Med Sci 1990;26:525-33

12 Sclarovsky S. Electrocardiography of acute myocardial ischaemic syndromes. London: Martin Dunitz, 1999.

13 Birnbaum Y, Wagner GS. The Initial electrocardiographic pattern in acute myocardial infarction: correlation with infarct size. J Electrocardiol 1999:32 (suppl): 122-8

14 Holland R, Brooks H. The QRS complex during myocardial ischemia: an experimental analysis in the porcine heart. J Clin Invest 1976;57:541-50

15 David D, Naito M, Michelson E, et al. Intramyocardial conduction: a major determinant of $R$ wave amplitude during acute myocardial ischemia Circulation 1982:65:161-7.

16 Spekhorst H, SippensGroenewegen A, David G, et al. Body surface mapping during percutaneous transluminal coronary angioplasty. QRS changes indicating regional myocardial conduction delay. Circulation 1990:81:840-9.

17 Barnhill JE, Tendera M, Cade H, et al. Depolarization changes early in the course of myocardial infarction: significance of changes in the terminal portion of the QRS complex. J Am Coll Cardiol 1989;14:143-9.

18 Wagner N, Sevilla D, Krucoff $M$, et al. Transient alterations of the QRS complex and ST segment during percutaneous transluminal balloon angioplasty of the left anterior descending coronary artery. Am J Cardio 1988;62:1038-42.

19 DeHaan R. Differentiation of the atrioventricular conducting system of the heart. Circulation 1961:24:458-70.

20 Schiebler T, Stark M, Caesar R. Die stoffwechselsitation des reizleitungssystems. Klin Wochenschr 1956;34:181-3.

21 Feldman T, Chua KG, Childers RW. R wave of the surface and intracoronary electrogram during acute coronary artery occlusion. Am J Cardiol 1986:58:885-90

22 Birnbaum Y, Sclarovsky S, Blum A, et al. Prognostic significance of the initial electrocardiographic pattern in a first acute anterior wall myocardial infarction. Chest 1993;103:1681-7.
23 Birnbaum Y, Herz I, Sclarovsky S, et al. Prognostic significance of the admission electrocardiogram in acute myocardial infarction. J Am Coll Cardiol 1996;27: 1 128-32.

24 Birnbaum Y, Kloner R, Sclarovsky S, et al. Distortion of the terminal portion of the QRS on the admission electrocardiogram in acute myocardial infarction and correlation with infarct size and long term prognosis (Thrombolysis In Myocardial Infarction 4 Trial). Am J Cardiol 1996;78:396-403

25 Birnbaum Y, Maynard C, Wolfe S, et al. Terminal QRS distortion on admission is better than ST-segment measurements in predicting final infarct size and assessing the potential effect of thrombolytic therapy in anterior wall acute myocardial infarction. Am J Cardiol 1999;84:530-4.

26 Garcia-Rubira JC, Perez-Leal I, Garcia-Martinez JT, et al. The initial electrocardiographic pattern is a strong predictor of outcome in acute myocardial infarction. Int J Cardiol 1995;51:301-5.

27 Rude RF, Poole KW, Muller JE, et al. Electrocardiographic and clinical criteria for recognition of acute myocardial infarction based on analysis of 3,697 patients. Am J Cardiol 1983:52:936-42.

28 Brush JEJ, Brand DA, Acampora D, et al. Use of the initial electrocardiogram to predict in-hospital complications of acute myocardial infarction. N Engl J Med 1985;312:1 137-41.

29 Lee TH, Rouan GW, Weisberg MC, et al. Sensitivity of routine clinical criteria for diagnosing myocardial infarction within 24 hours of hospitalization. Ann Intern Med 1987; 106:181-6.

30 Gibler WB, Young GP, Hedges JR, et al. Acute myocardial infarction in chest pain patients with nondiagnostic ECGs: serial CK-MB sampling in the emergency department. The Emergency Medicine Cardiac Research Group. Ann Emerg Med 1992;21:504-12.

31 Hedges JR, Young GP, Henkel GF, et al. Serial ECGs are less accurate than serial $C K-M B$ results for emergency department diagnosis of myocardial infarction. Ann Emerg Med 1992;21:1445-50.

32 Menown IB, Mackenzie G, Adgey AA. Optimizing the initial 12-lead electrocardiographic diagnosis of acute myocardial infarction. Eur Heart J 2000;21:275-83.

33 Birnbaum Y, Kloner RA. Clinical aspects of myocardial stunning. Coron Artery Dis 1995;6:606-12.

$34 \mathrm{Kaul} \mathrm{S}$. There may be more to myocardial viability than meets the eye! Circulation 1995;92:2790-3.

35 Aldrich H, Wagner N, Boswick J, et al. Use of initial ST-segment deviation for prediction of final electrocardiographic size of acute myocardial infarcts. Am J Cardiol 1988;61:749-53.

36 Clemmensen $\mathbf{P}$, Grande $\mathrm{P}$, Aldrich $\mathrm{H}$, et al. Evaluation of formulas for estimating the final size of acute myocardial infarcts from quantitative ST-segment elevation on the initial standard 12-lead ECG.J Electrocardiol 1991;24:77-83.

37 Christian T, Gibbons R, Clements I, et al. Estimates of myocardium at risk and collateral flow in acute myocardial infarction using electrocardiographic indexes with comparison to radionuclide and angiographic measures. J Am Coll Cardiol 1995;26:388-93.

38 Clements I, Kaufmann P, Bailey K, et al. Electrocardiographic prediction of myocardial area at risk. Mayo Clin Proc 1991;66:985-90.

39 Willems JL, Willems RJ, Willems GM, et al. Significance of initial ST segment elevation and depression for the management of thrombolytic therapy in acute myocardial infarction. Circulation 1990;82:1147-58.

40 Vermeer F, Simoons ML, Bar FW, et al. Which patients benefit most from early thrombolytic therapy with intracoronary streptokinase? Circulation 1986;74:1379-89.

41 Birnbaum Y, Criger DA, Wagner GS, et al. Prediction of the extent and severity of left ventricular dysfunction in anterior acute myocardial infarction by the admission electrocardiogram. Am Heart J 2001;141:915-24.

42 Roberts WC, Gardin JM. Location of myocardial infarcts: a confusion of terms and definitions. Am J Cardiol 1978;42:868-72.

43 Huey BL, Beller GA, Kaiser DL, et al. A comprehensive analysis of myocardial infarction due to left circumflex artery occlusion: comparison with infarction due to right coronary artery and left anterior descending artery occlusion. J Am Coll Cardiol 1988;12:1 156-66.

44 Sclarovsky S, Topaz O, Rechavia E, et al. Ischemic ST segment depression in leads V2-V3 as the presenting electrocardiographic feature of posterolateral wall myocardial infarction. Am Heart J 1987; 1 13: 1085-90.

45 Geft IL, Shah PK, Rodriguez L, et al. ST elevations in leads V1 to V5 may be caused by right coronary artery occlusion and acute right ventricular infarction. Am J Cardiol 1984:53:991-6.

46 Juergens CP, Fernandes C, Hasche ET, et al. Electrocardiographic measurement of infarct size after thrombolytic therapy. J Am Coll Cardiol 1996;27:617-24

47 Hasche ET, Fernandes C, Freedman SB, et al. Relation between ischemia time, infarct size, and left ventricular function in humans. Circulation 1995;92:710-19.

48 Birnbaum Y, Mahaffey KW, Criger DA, et al. Grade III ischemia on presentation with acute myocardial infarction predicts rapid progression of necrosis and less myocardial salvage with thrombolysis. Cardiology 2002:97:166-74

49 Shah PK, Pichler M, Berman DS, et al. Noninvasive identification of a high risk subset of patients with acute inferior myocardial infarction. Am J Cardiol 1980;46:915-21

50 Gibson RS, Crampton RS, Watson DD, et al. Precordial ST-segment depression during acute inferior myocardial infarction: clinical, scintigraphic and angiographic correlations. Circulation 1982:66:732-41.

51 Croft $\mathrm{CH}$, Woodward W, Nicod P, et al. Clinical implications of anterior S-T segment depression in patients with acute inferior myocardial infarction. Am J Cardiol 1982;50:428-36. 
52 Gelman JS, Saltrups A. Precordial ST segment depression in patients with inferior myocardial infarction: clinical implications. Br Heart J 1982:48:560-5.

53 Jennings K, Reid DS, Julian DG. "Reciprocal" depression of the ST segment in acute myocardial infarction. BMU 1983;287:634-7.

54 Roubin GS, Shen WF, Nicholson M, et al. Anterolateral ST segment depression in acute inferior myocardial infarction: angiographic and clinical implications. Am Heart J 1984;107:1177-82.

55 Cohen $\mathbf{M}$, Blanke H, Karsh KR, et al. Implications of precordial ST segment depression during acute inferior myocardial infarction: arteriographic and ventriculographic correlations during the acute phase. Br Heart J 1984:52:497-501.

56 Berland J, Cribier A, Bahar P, et al. Anterior ST depression in inferior myocardial infarction: correlation with results of intracoronary thrombolysis. Am Heart J 1986;111:481-8.

57 Ruddy TD, Yasuda T, Gold HK, et al. Anterior ST segment depression in acute inferior myocardial infarction as a marker of greater inferior, apical, and posterolateral damage. Am Heart J 1986;112:1210-16.

58 Ong L, Valdellon B, Coromilas J, et al. Precordial S-T segment depression in inferior myocardial infarction: evaluation by quantitative thallium-201 scintigraphy and technetium-99m ventriculography. Am J Cardiol 1983;51:734-9.

59 Goldberg HL, Borer JS, Jacobstein JG, et al. Anterior S-T segmen depression in acute inferior myocardial infarction: indicator of posterolateral infarction. Am J Cardiol 1981:48:1009-15.

60 Billadello JJ, Smith JL, Ludbrook PA, et al. Implications of "reciprocal" ST segment depression associated with acute myocardial infarction identified by positron tomography. J Am Coll Cardiol 1983;2:616-24

61 Ferguson DW, Pandian N, Kroschos M, et al. Angiographic evidence that reciprocal ST segment depression during acute myocardial infarction does not indicate remote ischemia: analysis of 23 patients. Am J Cardiol 1984;53:55-62.

62 Rutledge JC, Amsterdam EA, Bogren $\mathrm{H}$, et al. Anterior ST segment depression associated with acute inferior myocardial infarction: clinical, hemodynamic and angiographic correlates. Am I Noninvas Cardiol 1987; 1:290-5

63 Birnbaum Y, Herz I, Sclarovsky S, et al. Prognostic significance of precordial ST segment depression on admission electrocardiogram in patients with inferior wall myocardial infarction. J Am Coll Cardiol 1996;28:313-18.

64 Tsuka Y, Sugiura T, Hatada K, et al. Clinical characteristics of ST-segment elevation in lead V6 in patients with $Q$-wave acute inferior wall myocardial infarction. Coron Artery Dis 1999:10:465-9.

65 Matetzky S, Freimark D, Chouraqui P, et al. Significance of ST segment elevations in posterior chest leads (V7' to V9) in patients with acute inferior myocardial infarction: application for thrombolytic therapy. J Am Coll Cardiol 1998;31:506-11.

66 Fisch C. Electrocardiography. In: Braunwald E, ed. Heart disease. A textbook of cardiovascular medicine. 5th Ed. Philadelphia: W B Saunders, 1997: 109-52.

67 Raitt M, Maynard C, Wagner G, et al. Appearance of abnormal Q waves early in the course of acute myocardial infarction: implications for efficacy of thrombolytic therapy. J Am Coll Cardiol 1995;25:1084-8.

68 Bar FW, Vermeer F, de Zwaan C, et al. Value of admission electrocardiogram in predicting outcome of thrombolytic therapy in acute myocardial infarction. A randomized trial conducted by The Netherlands Interuniversity Cardiology Institute. Am J Cardiol 1987;59:6-13.

69 Timmis G. Electrocardiographic effects of reperfusion. Cardiol Clin 1987:5:427-45.

70 Goldberg S, Urban P, Greenspon A, et al. Limitation of infarct size with thrombolytic agents-electrocardiographic indexes. Circulation 1983;68(suppl I):177-182

71 Rechavia E, Blum A, Mager A, et al. Electrocardiographic Q-waves inconstancy during thrombolysis in acute anterior wall myocardial infarction. Cardiology 1992;80:392-8

72 Bateman TM, Czer LSC, Gray R, et al. Transient pathologic Q waves during acute ischemic events: an electrocardiographic correlate of during acute ischemic events: an electrocardiographic correlate of

73 Gross H, Rubin IL, Laufer H, et al. Transient abnormal Q waves in the dog without myocardial infarction. Am J Cardiol 1964;14:669-74.

74 Przybojewski JZ, Thrope L. Transient "pathologic" Q-waves occuring during exercise testing: assessment of their clinical significance in a presentation of a series of patients. J Electrocardiol 1987;20:121-30.

75 Raitt MH, Maynard C, Wagner GS, et al. Relation between symptom duration before thrombolytic therapy and final myocardial infarct size. Circulation 1996:93:48-53.

76 DePasquale NP, Burch GE, Phillips JH. Electrocardiograph alterations associated with electrically "silent" areas of myocardium. Am Heart J 1964;68:697-709.

77 Anderson JL, Marshall HW, Bray BE, et al. A randomized trial of intracoronary streptokinase in the treatment of acute myocardial infarction. N Engl J Med 1983;308:1312-18.

78 Wong CK, French JK, Aylward PE, et al. Usefulness of the presenting electrocardiogram in predicting successful reperfusion with streptokinase

79 Birnbaum Y, Chetrit A, Sclarovsky S, et al. Abnormal Q waves on the admission electrocardiogram of patients with first acute myocardial infarction: prognostic implications. Clin Cardiol 1997;20:477-81.

80 Matetzky S, Barabash Gl, Shahar A, et al. Early T wave inversion after thrombolytic therapy predicts better coronary perfusion: clinical and angiographic study. J Am Coll Cardiol 1994;24:378-83.

81 Herz I, Birnbaum Y, Zlotikamien B, et al. The prognostic implications of negative T waves in the leads with ST segment elevation on admission in acute myocardial infarction. Cardiology 1999;92:121-7.
82 Becker $\mathbf{R}$, Alpert J. Electrocardiographic ST segment depression in coronary heart disease. Am Heart J 1988; 115:862-8.

83 Cribier A, Korsatz L, Koning R, et al. Improved myocardial ischemic response and enhanced collateral circulation with long repetitive coronary occlusion during angioplasty: a prospective study. J Am Coll Cardiol 1992;20:578-86.

84 Mizuno K, Horiuchi K, Matui $\mathrm{H}$, et al. Role of coronary collateral vessels during transient coronary occlusion during angioplasty assessed by hrmodynamic, electrocardiographic and metabolic changes. J Am Coll Cardiol 1988; 12:624-8.

85 Cohen M, Rentrop P. Limitation of myocardial ischemia by collateral circulation during sudden controlled coronary artery occlusion in human subjects: a prospective study. Circulation 1986;74:469-76

86 Deutsch E, Berger M, Kussmaul W, et al. Adaptation to ischemia during percutaneous transluminal coronary angioplasty. Clinical, hemodynamic and metabolic features. Circulation 1990:82:2044-51.

87 Birnbaum Y, Hale SL, Kloner RA. Progressive decrease in the ST segment elevation during ischemic preconditioning: is it related to recruitment of collateral vessels? J Mol Cell Cardiol 1996;28: 1493-9.

88 Sagie A, Sclarovsky S, Strasberg B, et al. Acute anterior wall myocardia infarction presenting with positive T waves and without ST segment shift. Electrocardiographic features and angiographic correlation. Chest 1989;95:1211-15.

89 Birnbaum Y, Solodky A, Herz I, et al. Implication of inferior ST segment depression in anterior acute myocardial infarction: electrocardiographic and angiographic correlation. Am Heart J 1994;127:1467-73.

90 Sclarovsky S, Birnbaum Y, Solodky A, et al. Isolated mid-anterior myocardial infarction: a special electrocardiographic sub-type of acute myocardial infarction consisting of ST-elevation in non-consecutive leads and two different morphologic types of ST-depression. Int J Cardiol 1994:46:37-47.

91 Fletcher WO, Gibbons RJ, Clements IP. The relationship of inferior ST depression, lateral ST elevation, and left precordial ST elevation to myocardium at risk in acute anterior myocardial infarction. Am Heart J 1993; 126:526-35

92 Arbane M, Goy JJ. Prediction of the site of total occlusion in the left anterior descending coronary artery using admission electrocardiogram in anterior wall acute myocardial infarction. Am J Cardiol 2000:85:487-91.

93 Birnbaum Y, Sclarovsky S, Mager A, et al. ST segment depression in aVL: a sensitive marker for acute inferior myocardial infarction. Eur Heart J 1993; 14:4-7

94 Lew AS, Maddahi J, Shah PK, et al. Factors that determine the direction and magnitude of precordial ST-segment deviations during inferior wall acute myocardial infarction. Am J Cardiol 1985;55:883-8.

95 Lew AS, Weiss AT, Shah PK, et al. Precordial ST segment depression during acute inferior myocardial infarction: early thallium-201 scintigraphic evidence of adjacent posterolateral or inferoseptal involvement. J Am Coll Cardiol 1985;5:203-9.

96 Pierard LA, Spynger M, Gilis F, et al. Significance of precordial ST-segment depression in inferior acute myocardial infarction as determined by echocardiography. Am J Cardiol 1986:57:82-5.

97 Putini RL, Natale E, Ricci R, et al. Dipyridamole echocardiography evaluation of acute inferior myocardial infarction with concomitant anterior ST segment depression. Eur Heart J 1993;14:1328-33.

98 Peterson ED, Hathaway WR, Zabel M, et al. Prognostic significance of precordial ST segment depression during inferior myocardial infarction in the thrombolytic era: results in 16,521 patients. J Am Coll Cardiol 1996;28:305-12.

99 Hasdai D, Birnbaum Y, Porter A, et al. Maximal precordial ST-segment depression in leads V4-V6 in patients with inferior wall acute myocardial infarction indicates coronary artery disease involving the left anterior descending coronary artery system. Int J Cardiol 1997;58:273-8.

100 Boden WE, Kleiger RE, Gibson RS, et al. Electrocardiographic evolution of posterior acute myocardial infarction: importance of early precordial ST-segment depression. Am J Cardiol 1987:59:782-7.

101 Porter A, Vaturi M, Adler Y, et al. Are there differences among patients with inferior acute myocardial infarction with ST depression in leads V2 and $\mathrm{V} 3$ and positive versus negative $T$ waves in these leads on admission? Cardiology 1998;90:295-8.

102 Blanke H, Cohen M, Schlueter GU, et al. Electrocardiographic and coronary arteriographic correlations during acute myocardial infarction. Am J Cardiol 1984;54:249-55.

103 Aldrich HR, Hindman NB, Hinohara $T$, et al. Identification of the optimal electrocardiographic leads for detecting acute epicardial injury in acute myocardial infarction. Am J Cardiol 1987:59:20-3.

104 Coma-Canella I, Lopez-Sendon J, Alcasena S, et al. Electrocardiographic alterations in leads $\mathrm{V} 1$ to $\mathrm{V} 3$ in the diagnosis of right and left ventricular infarction. Am Heart J 1986;112:940-6.

105 Porter A, Herz I, Strasberg B. Isolated right ventricular infarction presenting as anterior wall myocardial infarction on electrocardiography. Clin Cardiol 1997:20:971-3.

106 Ben-Gal T, Herz I, Solodky A, et al. Acute anterior wall myocardial infarction entailing ST-segment elevation in lead V1: electrocardiographic and angiographic correlations. Clin Cardiol 1998;21:399-404

107 Birnbaum Y, Hasdai D, Sclarovsky S, et al. Acute myocardial infarction entailing ST segment elevation in lead aVL: electrocardiographic differentiation among occlusion of the left anterior descending, firs diagonal, and first obtuse marginal coronary arteries. Am Heart J 1996:131:38-42.

108 Birnbaum Y, Sclarovsky S, Solodky A, et al. Prediction of the level of left anterior coronary artery obstruction during acute anterior wall 
myocardial infarction by the admission electrocardiogram. Am J Cardiol 1993:72:823-6.

109 Engelen DJ, Gorgels AP, Cheriex EC, et al. Value of the electrocardiogram in localizing the occlusion site in the left anterior descending coronary artery in acute anterior myocardial infarction. J Am Coll Cardiol 1999;34:389-95

110 Sasaki K, Yotsukura M, Sakata K, et al. Relation of ST-segment changes in inferior leads during anterior wall acute myocardial infarction to length and occlusion site of the left anterior descending coronary artery. Am J Cardiol 2001;87:1340-5.

111 Haraphongse $\boldsymbol{M}$, Tanomsup S, Jugdutt BI. Inferior ST segment depression during acute anterior myocardial infarction: clinical and angiographic correlations. J Am Coll Cardiol 1984;4:467-76.

112 Birnbaum Y, Herz I, Solodky A, et al. Can we differentiate by the admission ECG between anterior wall acute myocardial infarction due to a left anterior descending artery occlusion proximal to the origin of the first septal branch and a postseptal occlusion? Am J Noninvas Cardiol 1994;8:115-19.

113 Porter A, Wyshelesky A, Strasberg B, et al. Correlation between the admission electrocardiogram and regional wall motion abnormalities as detected by echocardiography in anterior acute myocardial infarction. Cardiology 2000;94: 1 18-26

114 Sapin PM, Musselman DR, Dehmer GJ, et al. Implications of inferior ST-segment elevation accompanying anterior wall acute myocardial infarction for the angiographic morphology of the left anterior descending coronary artery morphology and site of occlusion. Am J Cardiol 1992;69:860-5.

115 Tamura A, Kataoka H, Nagase K, et al. Clinical significance of inferior ST elevation during acute anterior myocardial infarction. Br Heart $J$ 1995;74:611-14

116 Braat SH, Brugada P, den Dulk K, et al. Value of lead V4R for recognition of the infarct coronary artery in acute inferior myocardial infarction. Am J Cardiol 1984;53:1538-41.

117 Kontos MC, Desai PV, Jesse RL, et al. Usefulness of the admission electrocardiogram for identifying the infarct-related artery in inferior wall acute myocardial infarction. Am J Cardiol 1997;79:182-4.

118 Bairey CN, Shah PK, Lew AS, et al. Electrocardiographic differentiation of occlusion of the left circumflex versus the right coronary artery as a cause of inferior acute myocardial infarction. Am J Cardiol 1987;60:456-9.

119 Herz I, Assali AR, Adler Y, et al. New electrocardiographic criteria for predicting either the right or left circumflex artery as the culprit coronary artery in inferior wall acute myocardial infarction. Am J Cardiol artery in inferior wall

120 Hasdai D, Birnbaum Y, Herz l, et al. ST segment depression in lateral limb leads in inferior wall acute myocardial infarction. Implications regarding the culprit artery and the site of obstruction. Eur Heart $J$ 1995; 16:1549-53.

121 Kosuge M, Kimura K, Ishikawa T, et al. New electrocardiographic criteria for predicting the site of coronary artery occlusion in inferior wall acute myocardial infarction. Am J Cardiol 1998:82:1318-22.

122 Assali AR, Herz I, Vaturi M, et al. Electrocardiographic criteria for predicting the culprit artery in inferior wall acute myocardial infarction. Am J Cardiol 1999;84:87-9.

123 Zimetbaum PJ, Krishnan S, Gold A, et al. Usefulness of ST-segment elevation in lead III exceeding that of lead II for identifying the location of the totally occluded coronary artery in inferior wall myocardial infarction. Am J Cardiol 1998:81:918-19.

124 Birnbaum Y, Hale SL, Kloner RA. Changes in R wave amplitude: ECG differentiation between episodes of reocclusion and reperfusion associated with ST-segment elevation. J Electrocardiol 1997;30:211-16.

125 Kopelman HA, Forman MB, Wilson BH, et al. Right ventricular myocardial infarction in patients with chronic lung disease: possible role of right ventricular hypertrophy. J Am Coll Cardiol 1985;5:1302-7.

126 Erhardt LR, Sjogren A, Wahlberg I. Single right-sided precordial lead in the diagnosis of right ventricular involvement in inferior myocardial infarction. Am Heart J 1976;91:571-6.

127 Zehender M, Kasper W, Kauder E, et al. Right ventricular infarction as an independent predictor of prognosis after acute inferior myocardia infarction. N Engl J Med 1993;328:981-8.
128 Lopez-Sendon J, Coma-Canella I, Alcasena S, et al. Electrocardiographic findings in acute right ventricular infarction: sensitivity and specificity of electrocardiographic alterations in right precordial leads V4R, V3R, V1, V2, and V3. J Am Coll Cardiol 1985;6:1273-9.

129 Assali AR, Sclarobsky S, Herz I, et al. Comparison of patients with inferior wall acute myocardial infarction with versus without ST-segment elevation in leads V5 and V6. Am J Cardiol 1998:81:81-3.

130 Ruddy TD, Yasuda T, Gold HK. Correlations of regional wall motion and myocardial perfusion in patients with and without anterior precordial ST segment depression during acute inferior myocardial infarction. Am J Noninvas Cardiol 1987;1:81-7.

131 Boden WE, Bough EW, Korr KS, et al. Inferoseptal myocardial infarction: another cause of precordial ST-segment depression in transmural inferior wall myocardial infarction? Am J Cardiol 1984;54:1216-23.

132 Mukharii J, Murray S, Lewis SE, et al. Is anterior ST depression with acute transmural inferior infarction due to posterior infarction? A vectorcardiographic and scintigraphic study. J Am Coll Cardiol 1984;4:28-34

133 Haraphongse M, Jugdutt BI, Rossall RE. Significance of precordial ST-segment depression in acute transmural inferior infarction: coronary angiographic findings. Cathet Cardiovasc Diagn 1983;9:143-51

134 Hlatky MA, Califf RM, Lee KL, et al. Prognostic significance of precordial ST-segment depression during inferior acute myocardial infarction. Am J Cardiol 1985:55:325-9.

135 Hasdai D, Sclarovsky S, Solodky A, et al. Prognostic significance of maximal precordial ST-segment depression in right (V1 to V3) versus left (V4 to V6) leads in patients with inferior wall acute myocardial infarction. Am J Cardiol 1994;74:1081-4

136 Salcedo JR, Baird MG, Chambers RJ, et al. Significance of reciprocal $\mathrm{S}-\mathrm{T}$ segment depression in anterior precordial leads in acute inferior myocardial infarction: concomitant left anterior descending coronary artery disease? Am J Cardiol 1981;48:1003-8.

137 Agarwal JB, Khaw K, Aurignac F, et al. Importance of posterior chest leads in patients with suspected myocardial infarction, but nondiagnostic routine 12-lead electrocardiogram. Am J Cardiol 1999;83:323-6.

138 Casas RE, Marriott HJ, Glancy DL. Value of leads V7-V9 in diagnosing posterior wall acute myocardial infarction and other causes of tall $R$ waves in V1-V2. Am J Cardiol 1997:80:508-9.

139 Matetzky S, Freimark D, Feinberg MS, et al. Acute myocardial infarction with isolated ST-segment elevation in posterior chest leads V7-9: "hidden" ST-segment elevations revealing acute posterior infarction. $J$ Am Coll Cardiol 1999;34:748-53.

140 Wung SF, Drew BJ. New electrocardiographic criteria for posterior wall acute myocardial ischemia validated by a percutaneous transluminal coronary angioplasty model of acute myocardial infarction. Am J Cardiol $2001 ; 87: 970-4$

141 Mager A, Sclarovsky S, Herz l, et al. Value of the initial electrocardiogram in patients with inferior-wall acute myocardial infarction for prediction of multivessel coronary artery disease. Coron Artery Dis 2000;11:415-20.

142 Birnbaum Y, Goodman S, Barr A, et al. Comparison of primary coronary angioplasty versus thrombolysis in patients with ST-segment elevation acute myocardial infarction and grade II and grade III myocardial ischemia on the enrollment electrocardiogram. Am J Cardiol 2001;88:842-7.

143 Lee CW, Hong M-K, Yang H-S, et al. Determinants and prognostic implications of terminal QRS complex distortion in patients treated with primary angioplasty for acute myocardial infarction. Am J Cardiol 2001;88:210-13

144 Birnbaum Y, Herz I, Sclarovsky S, et al. Admission clinical and electrocardiographic characteristics predicting an increased risk for early reinfarction after thrombolytic therapy. Am Heart J 1998;135:805-12.

145 Aversano T, Aversano LT, Passamani E, et al. Thrombolytic therapy vs primary percutaneous coronary intervention for myocardial infarction in patients presenting to hospitals without on-site cardiac surgery: a randomized controlled trial. JAMA 2002;287:1943-51. 